\title{
Conformational Preference and Chiroptical Response of Carbohydrates D-Ribose and 2-Deoxy-D-ribose in Aqueous and Solid Phases
}

\author{
María Mar Quesada-Moreno, ${ }^{\dagger}$ Luis Miguel Azofra, ${ }^{\ddagger}$ Juan Ramón Avilés-Moreno, $^{\S}$ Ibon Alkorta,** \\ José Elguero, ${ }^{\ddagger}$ and Juan Jesús López-González ${ }^{* \dagger}$
${ }^{\dagger}$ Department of Physical and Analytical Chemistry, University of Jaén, Campus Las Lagunillas, E-23071 Jaén, Spain Cedex, France \\ ${ }^{\ddagger}$ Instituto de Química Médica (C.S.I.C.), Juan de la Cierva, 3, E-28006 Madrid, Spain \\ ${ }^{\S}$ Laboratoire de Physique des Lasers, Atomes et Molécules, UMR 8523 CNRS - Université Lille I, Bât. P5, 59655 Villeneuve d'Ascq
}

\section{Supporting Information}

ABSTRACT: This work targets the structural preferences of D-ribose and 2-deoxy-D-ribose in water solution and solid phase. A theoretical DFT (B3LYP and M06-2X) and MP2 study has been undertaken considering the five possible configurations (open-chain, $\alpha$-furanose, $\beta$-furanose, $\alpha$-pyranose, and $\beta$-pyranose) of these two carbohydrates with a comparison of the solvent treatment using only a continuum solvation model (PCM) and the PCM plus one explicit water molecule. In addition, experimental vibrational studies using both nonchiroptical (IR-Raman) and chiroptical (VCD) techniques have been carried out. The theoretical and experimental results show that $\alpha$ - and $\beta$-pyranose forms are the dominant configurations for both compounds. Moreover, it has been found that 2-deoxy-D-ribose presents a non-negligible percentage of open-chain forms in aqueous solution, while in solid phase this configuration is absent.

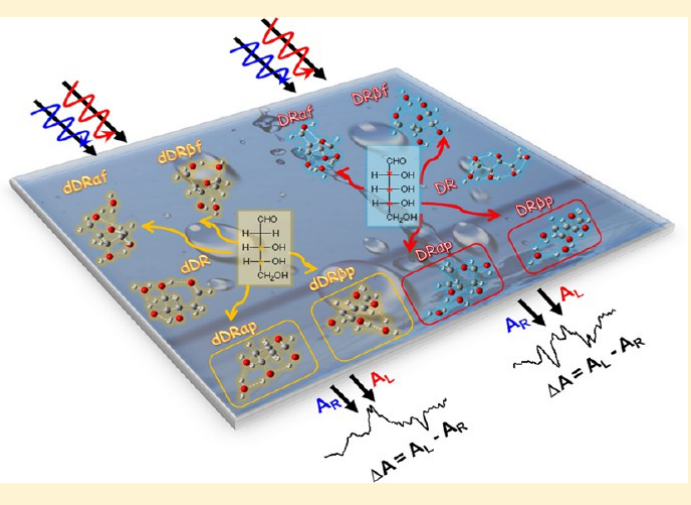

\section{INTRODUCTION}

Carbohydrates of general formula $\mathrm{C}_{n} \mathrm{H}_{2 n} \mathrm{O}_{n}$ with $n \geq 2$ (the deoxy derivatives have $\mathrm{O}_{n-1}$ oxygen atoms) are the most abundant organic compounds on earth by mass, with a string of relevant functions as energy storage, metabolic intermediates, and structural building blocks. Sugars with $n \geq 5$ are present in several forms of life, building up most of the bioorganic matter. ${ }^{1-3}$ D-Ribose and 2-deoxy-D-ribose are constituents of the nucleic acids RNA and DNA, respectively, and for this reason they are so relevant in biochemistry. The structure of D-ribose and 2-deoxy-D-ribose differs by the presence/absence of a hydroxyl group on C2 (Figure 1). Their interactions with

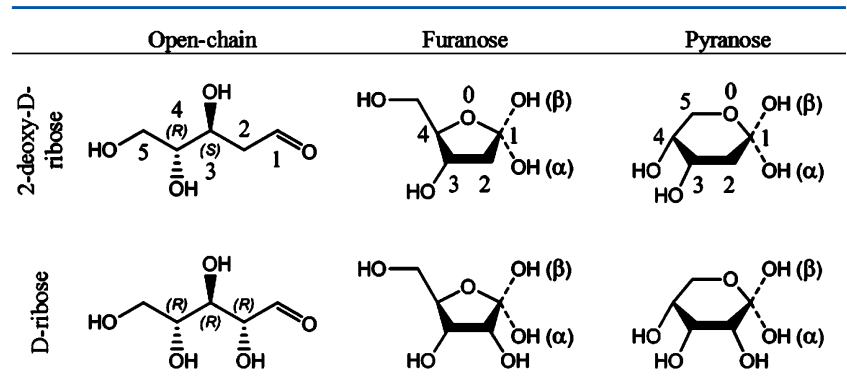

Figure 1. Left to right and top to bottom: open-chain, furanose, and pyranose $(\alpha$ - and $\beta$-) configurations of 2-deoxy-D-ribose and D-ribose. The absolute configuration of the stereogenic centers is indicated in the linear forms. The numbering of 2-deoxy-D-ribose structures (extends to D-ribose) corresponds to the IUPAC recommendation. water are very important because they affect the stabilities of native configurations of RNA and DNA. ${ }^{4}$ Due to their importance in nucleic acids and due to the fact that they are in the human body surrounded by water, the study of the structures of these compounds in water is of considerable interest.

D-Ribose and 2-deoxy-D-ribose can exist in five forms, i.e., one open-chain, two with five-membered rings, $\alpha$ - and $\beta$-furanoses, and two with six-membered rings, $\alpha$ - and $\beta$-pyranoses (Figure 1). ${ }^{5}$ Ribose is usually described as furanose anomers, predominant in ribonucleosides, RNA, ATP, and other biochemical derivatives. The conformational landscape and the flexibility of many carbohydrates have been analyzed by DFT and $a b$ initio methods. ${ }^{1,2,6-12}$ It is noteworthy that there is a good amount of structural data for D-ribose, but little to none for the isolated 2-deoxy-D-ribose. These statements will be discussed in the following paragraph. A theoretical study of the conformational profile of the methyl $\beta$-D-2-deoxyribofuranoside and methyl $\beta$-D-ribofuranoside was carried out using DFT methods and the influence of the conformation on the nuclear chemical shifts was analyzed. ${ }^{13}$

We have found some papers about structural studies of D-ribose and 2-deoxy-D-ribose. Concerning D-ribose, Jalbout et al.

Received: May 24, 2013

Revised: October 15, 2013

Published: October 17, 2013 
reported a computational analysis of the isolated $\beta$-furanose form of D-ribose. ${ }^{14}$ Cocinero et al. ${ }^{3}$ studied D-ribose in gas phase with a combination of quantum chemical calculations and FT-MW (Fourier-transform microwave) spectroscopy. They concluded that the $\alpha$ - and $\beta$-pyranose forms in this carbohydrate are more stable than the furanose forms. These authors were able to characterize six structures of $\alpha$ - and $\beta$-pyranose in an energy range of $2 \mathrm{~kJ} \mathrm{~mol}^{-1}$, which indicates the conformational complexity of this carbohydrate. Moreover, Angyal concluded that 58\% of $\beta$-anomers is in the pyranose form and $13 \%$ of $\beta$-anomers is in the furanose form in solution by the use of NMR spectroscopy. ${ }^{15}$ Mathlouthi et al. ${ }^{16}$ analyzed the IR and Raman spectra of D-ribose and 2-deoxy-D-ribose in aqueous solution. They concluded that D-ribose was present in $76 \%$ pyranose and $24 \%$ furanose forms, though they do not report percentages for 2-deoxy-D-ribose. Yaylayan et al. ${ }^{17}$ studied the enolization and carbonyl group migration of selected aldoses and ketoses with the use of IR spectroscopy. They analyzed these species in $\mathrm{D}_{2} \mathrm{O}$ as a function of concentration and temperature, between 30 and $80{ }^{\circ} \mathrm{C}$, and they observed two relevant bands for these two carbohydrates. For D-ribose, the first one at $1722 \mathrm{~cm}^{-1}$, assigned to the $\mathrm{C}=\mathrm{O}$ stretching of the carbonyl group, and the second one at $1646 \mathrm{~cm}^{-1}$, which corresponded to the $\mathrm{C}=\mathrm{C}$ stretching of the enediol group. The enediol species were formed as a result of an enolization of acyclic aldehyde and keto forms of the carbohydrates. The ratio of intensities of enediol to carbonyl absorption bands decreases with temperature and increases with concentration. Šišak et al. ${ }^{18}$ studied the structure of D-ribose in solid phase using both NMR spectroscopy and X-ray diffraction techniques. The molecules in the crystal presented the pyranose ring structure, with a $\beta / \alpha$ ratio of $2: 1$ and $3: 1$ according to the analysis of the powder and single-crystal, respectively. Moreover, the melted and newly recrystallized sample showed a $\beta / \alpha$ ratio of $2.5: 1$. The authors pointed out that the reliability of the calculated $\beta / \alpha$ ratios is difficult to estimate, as the ratios were determined from different experiments.

For 2-deoxy-D-ribose, Lemieux et al. ${ }^{19}$ studied its mutarotation in $\mathrm{H}_{2} \mathrm{O}$ and $\mathrm{D}_{2} \mathrm{O}$ solutions by ${ }^{1} \mathrm{H}$ NMR spectroscopy and OR (optical rotatory) measurements. They concluded that this carbohydrate rearranges, giving an equilibrium mixture which contains the $\alpha$ - and $\beta$-pyranose and furanose anomers in the approximate percentage ratios of $43(\beta \mathrm{p}): 42(\alpha \mathrm{p}): 10(\beta \mathrm{f})$ : $5(\alpha \mathrm{f})$ at $0{ }^{\circ} \mathrm{C}$ and $30(\beta \mathrm{p}): 30(\alpha \mathrm{p}): 18(\beta \mathrm{f}): 22(\alpha \mathrm{f})$ at $90{ }^{\circ} \mathrm{C}$. For 2-deoxy-D-ribose, Yaylayan et al. ${ }^{17}$ reported that the first band was observed at $1715 \mathrm{~cm}^{-1}$ and the second one was absent.

The chiral response of the 2-deoxy-D-ribose has not been studied yet, however, some studies exist in the case of the D-ribose. Thus, Tummalapalli et al. ${ }^{20}$ recorded the IR and VCD spectra of simple carbohydrates, including D-ribose, in DMSO$d_{6}$ solutions in the $1650-800 \mathrm{~cm}^{-1}$ region. They eliminated the presence of artifacts in the VCD spectrum equilibrating a given enantiomer with $\mathrm{H}_{2} \mathrm{O}$ or $\mathrm{D}_{2} \mathrm{O}$ and lyophilizing the equilibrated solution. The authors point out the difficulty of the identification of all the structures participating in the VCD features. Besides, Bose et al. ${ }^{21}$ analyzed the IR and VCD spectra of the D-ribose and several monosaccharides in DMSO- $d_{6}$ solutions in the $1500-1180 \mathrm{~cm}^{-1}$ region. The authors conclude for D-ribose, among other monosaccharides, that this carbohydrate exits in both pyranose and furanose forms. The VCD spectra of other carbohydrates have been analyzed by Polavarapu and co-workers, ${ }^{22}$ using films formed from aqueous solutions of D-glucose or D-allose in the $2000-900 \mathrm{~cm}^{-1}$ region while Monde and co-workers ${ }^{23}$ reported VCD studies of some disaccharides in the $\mathrm{CH}$ vibrational region. In addition, Wen et al. ${ }^{24}$ recorded the ROA spectra of D-ribose and of 14 monosaccharides in aqueous solution in the $1600-600 \mathrm{~cm}^{-1}$ spectral region. For D-ribose, they concluded that it exists probably in both pyranose and furanose forms, but a further analysis in the region below $700 \mathrm{~cm}^{-1}$ would be necessary to verify this point. All these results are empiric conclusions and they have been carried out without the help of the calculations.

In the past, most of the chemistry text books and handbooks showed the molecule of D-ribose in the $\beta$-furanose form, as present in biochemically important ribose derivatives. But it has been known from NMR spectroscopy and X-ray diffraction techniques that the molecules of D-ribose in the crystal present the pyranose ring structure. ${ }^{18}$ In addition, it has been shown from NMR observations that D-ribose exists in aqueous solutions as a mixture of $\alpha$ - and $\beta$-pyranoses and $\alpha$ - and $\beta$-furanoses with a predominance of the $\beta$-pyranose form. ${ }^{15}$ Moreover, Yaylayan et al. ${ }^{17}$ also found the presence of enediol in the open-chain structures, as well as the predominance of pyranoses and Lemieux et al. ${ }^{19}$ agree with a major proportion of pyranose forms of D-ribose in aqueous solutions but did not find evidence substantiating the presence of open-chain forms. Thus, all the studies in solution accomplished up to now for both monosaccharides agree on (i) the major presence of pyranoses; (ii) the minor presence of furanoses; and (iii) a negligible amount of open-chain structures (in both forms derived from the keto-enol tautomerism). At this point, we could summarize that it is clear that in solution, pyranose forms predominate over furanose ones and that a controversy remains about the presence of open-chain forms and about the $\alpha / \beta$ ratio of pyranose forms.

In order to clarify both the configurational preference and the conformational landscape of D-ribose and 2-deoxy-D-ribose in aqueous solution, in the present work, we carried out a detailed study of the structures of these two carbohydrates by quantum chemical calculations (thousands of structures have been modeled) coupled with chiral sensitive (VCD) and nonsensitive (IR and Raman) vibrational spectroscopies. The treatment of the solvent (water) has been modelized using only solvent continuum models (PCM) and PCM plus an explicit water molecule. In addition, we have also analyzed the experimental spectroscopic properties of these carbohydrates in solid phase.

\section{METHODS}

Theoretical Calculations. The conformational searches were conducted in two steps. In the first one, a large number of initial structures were chosen based on the different rotatable bonds (linear and cyclic forms) and the ring conformations (only in cyclic forms). Thus, in the open-chain configurations of 2-deoxy-D-ribose and D-ribose there are seven and eight rotatable bonds, respectively. For each rotatable bond, three possibilities have been considered: gauche, gauche', and trans $\left(g, g^{\prime}\right.$, and $\left.t\right)$ giving $2187\left(3^{7}\right)$ and $6561\left(3^{8}\right)$ initial structures, respectively. In the case of the furanose forms, twenty ring conformations (ten envelope and ten twist) were combined with the four and five rotatable bonds for $\alpha / \beta$-2-deoxy-Dribofuranose and $\alpha / \beta$-D-ribofuranose, respectively. Considering the three mentioned conformations $\left(g, g^{\prime}\right.$, and $\left.t\right)$ for the rotatable bonds, the total number of initial conformations is $1620\left(20 \cdot 3^{4}\right)$ and $4860\left(20 \cdot 3^{5}\right)$, respectively. Finally, for the pyranose structures, thirty-eight ring conformations (two chair, twelve half-chair, six skew, six boat, and twelve envelope) were combined with three and four rotatable bonds for $\alpha / \beta$-2-deoxy-D-ribopyranose 
and $\alpha / \beta$-D-ribopyranose, which corresponds to $1026\left(38 \cdot 3^{3}\right)$ and $3078\left(38 \cdot 3^{4}\right)$ initial structures, respectively. All these structures were optimized with the Becke, ${ }^{25}$ three-parameter, Lee-YangParr $^{26}$ density functional (B3LYP) and Pople's basis set 6-31G, ${ }^{27}$ taken into account the solvent effect through the use of the Polarizable Continuum Model (PCM) ${ }^{28}$ with the use of a dielectric constant $\varepsilon=78.36$, corresponding to water (PCM-water). Structures with a geometrical root-mean-square less than $0.05 \AA$ and electronic differences less than $0.1 \mathrm{~kJ} \mathrm{~mol}^{-1}$ were considered to be identical; duplicate structures are removed. ${ }^{1}$ The resulting geometries were optimized in a second step with two different functionals: on the one hand, the M06-2X,, 29 and on the other hand, the B3LYP ${ }^{25,26}$ hybrid functionals, and in both cases with the Pople's basis set $6-311++G(d, p)^{27}$ which includes diffuse and polarization functions for heavy and light atoms. The solvent effect has been simulated with the PCM-water method, ${ }^{30-34}$ including, in this case, the solute-solvent dispersion interaction energy, the solute-solvent repulsion interaction energy and the solute cavitation energy. All these structures were again compared to remove the repeated ones. Frequency calculations were carried out in order to confirm that the final structures correspond to real minima and to obtain the value of the Zero Point Energy (ZPE). The electronic energies have been corrected with the ZPE. In the most stable conformations, MP2(full)/6-311++G(3df,2p)//M06$2 \mathrm{X} / 6-311++\mathrm{G}(\mathrm{d}, \mathrm{p})$ single point calculations ${ }^{35-38}$ in PCM-water were performed to obtain more accurate energy values.

Finally, for each one of the most stable minima obtained at the M062X/6-311++G(d,p) computational level plus PCM, an explicit treatment of the solvent has been made by introducing one water molecule in several positions, pointing to each acidic and basic centers, that is, acting the water molecule as hydrogen bond acceptor (HBA) or donor (HBD), respectively. A total number of 701 geometries have been optimized for both carbohydrates using this methodology. The final number of nonredundant optimized structures was 229 for D-ribose and 144 for 2-deoxy-D-ribose.

All the DFT and MP2-calculations were carried out with the GAUSSIAN09 package. ${ }^{39}$ The ring puckering analysis methodology developed by Cremer and Pople ${ }^{40}$ was applied in order to characterize the pseudorotation parameters $(P, \theta, \phi)$, which overlaid on the Altona-Sundaralingam wheel-sphere, ${ }^{41}$ gives the type ring conformation, and the $Q$ amplitude, i.e., how much the ring is distorted with respect to the planar case. For this purpose, the RING $96^{40,42}$ and some in-house developed programs were employed. ${ }^{1}$

The electron density of the systems was analyzed within Atoms in Molecules (AIM) methodology ${ }^{43,44}$ with the MORPHY ${ }^{45-47}$ and AIMAll ${ }^{48}$ programs. On the basis of this methodology, all the interactions (covalent and weak interactions) were characterized by the presence of a bond critical point (BCP) and the corresponding bond path linking the two interacting nuclear attractors. The values of the electron density and its Laplacian at the BCP allow to classify the contacts as covalent or noncovalent. ${ }^{43,49,50}$ The Natural Bond Orbital (NBO $)^{51}$ theory was also applied for the orbital characterization of the weak interactions. These calculations were carried out with the NBO3.1 facilities. ${ }^{52}$ Finally, harmonic IR, Raman, and VCD calculations were computed.

\section{EXPERIMENTAL SECTION}

All the experimental techniques employed in this work belong to Scientific Central Services (CICT) of the University of Jaén. $^{53}$
A. Nonchiroptical Vibrational Spectroscopies (IR and Raman). The D-ribose and 2-deoxy-D-ribose were purchased from Sigma-Aldrich and used without further purification. IR and Raman spectra of $\mathrm{D}_{2} \mathrm{O}$ and $\mathrm{H}_{2} \mathrm{O}$ solutions $(4 \mathrm{M})$ were recorded.

A FT-IR 4100 JASCO spectrometer, equipped with a Globar source, a DGTS detector, and $\mathrm{KBr}$ optics, was used to record the IR spectra with the ATR accessory for the solid (powder) and liquid samples. The IR spectra were recorded in the 4000$500 \mathrm{~cm}^{-1}$ range, with 300 scans and a resolution of $1 \mathrm{~cm}^{-1}$ and $4 \mathrm{~cm}^{-1}$ for the solid (powder) and liquid samples, respectively.

The Raman spectra of D-ribose and 2-deoxy-D-ribose were recorded using a BRUKER MultiRAM Stand Alone FT-Raman Spectrometer, equipped with a $\mathrm{Nd}$ :YAG laser (excitation line at $1064 \mathrm{~nm}$ ) and a Ge detector cooled at liquid nitrogen temperature. The spectra of the solid samples (powder) were measured using a standard solid support with a resolution of $1 \mathrm{~cm}^{-1}$ and 200 scans. The spectra of the solutions were measured using standard liquid cells, with 300 scans and a resolution of $8 \mathrm{~cm}^{-1}$. All the spectra were recorded in the $4000-100 \mathrm{~cm}^{-1}$ spectral range.

B. Chiroptical Vibrational Spectroscopy (VCD). The VCD spectra of D-ribose and 2-deoxy-D-ribose in $4 \mathrm{M} \mathrm{D}_{2} \mathrm{O}$ and $\mathrm{H}_{2} \mathrm{O}$ solutions, in film, and in fluorolube and nujol mulls were recorded using a JASCO FVS-4000 FTIR spectrometer, equipped with InSb (4000-1900 $\mathrm{cm}^{-1}$ ) and MCT (2000$900 \mathrm{~cm}^{-1}$ ) detectors. To record the film spectra, more diluted solutions were used to get the optimum absorbance range for the VCD measurement of the sample.

The solvent was evaporated using $\mathrm{NaCl}$ "Real Crystal IR Sample Cards" ${ }^{54}$ in order to get very thin films. A few milligrams of the two samples were mixed with fluorolube or nujol mineral oils in order to get suitable mulls. Special attention is needed when working with solid samples in circular dichroism spectroscopy. ${ }^{55-57}$ In fact, we have measured the mulls in several positions by rotating the sample around both the beam propagation axes $\left(90^{\circ}\right.$ and $\left.180^{\circ}\right)$ and that perpendicular to it $\left(180^{\circ}\right)$ with the purpose to get the true VCD peaks and to be sure on the absence of artifacts in the recorded VCD spectra. ${ }^{55}$ The film spectra were recorded using a $\mathrm{KCl}$ support, with a resolution of 4$8 \mathrm{~cm}^{-1}$ and $14000-28000$ scans in blocks of 2000 scans. The remaining spectra were recorded using a standard cell equipped with $\mathrm{BaF}_{2}$ windows, with a resolution of $4-8 \mathrm{~cm}^{-1}$, path lengths of $6 \mu \mathrm{m}$ (for solution spectra) and 2000-16000 scans in blocks of 2000 scans. Concerning the baseline correction, we have subtracted the $\mathrm{D}_{2} \mathrm{O}, \mathrm{H}_{2} \mathrm{O}, \mathrm{KCl}$ support, nujol, and/or fluorolube signals to the VCD spectra.

\section{RESULTS AND DISCUSSION}

This section has been divided into four parts: the first one reports the theoretical study of the conformational landscape of 2-deoxy-D-ribose and D-ribose in aqueous solution models using only PCM and PCM plus an explicit water molecule. The second part describes the AIM and NBO analysis of the intramolecular weak interactions present in these compounds. The part three reports the experimental study of 2-deoxy-Dribose and D-ribose by nonchiroptical vibrational IR and Raman spectroscopies. Finally, the fourth part describes the chiroptical vibrational response using VCD spectroscopy. Along the description of the results the next abbreviations will be employed: $d D R, D R$, $\mathrm{dDR} \alpha \mathrm{f}, \mathrm{dDR} \beta \mathrm{f}, \mathrm{DR} \alpha \mathrm{f}, \mathrm{DR} \beta \mathrm{f}, \mathrm{dDR} \alpha \mathrm{p}, \mathrm{dDR} \beta \mathrm{p}, \mathrm{DR} \alpha \mathrm{p}$ and $\mathrm{DR} \beta \mathrm{p}$, which refer to open-chain 2-deoxy-D-ribose, open-chain D-ribose, 
Table 1. Conformational Search Summary

\begin{tabular}{|c|c|c|c|c|c|c|c|}
\hline \multirow[b]{2}{*}{ structure } & \multirow[b]{2}{*}{ initial } & \multirow[b]{2}{*}{ screen $^{a}$} & \multicolumn{3}{|c|}{ PCM/M06-2X } & \multicolumn{2}{|c|}{$\mathrm{PCM}+\mathrm{H} 2 \mathrm{O} / \mathrm{M} 06-2 \mathrm{X}$} \\
\hline & & & final $^{b}$ & $<10 \mathrm{~kJ} \mathrm{~mol}^{-1}$ & $<5 \mathrm{~kJ} \mathrm{~mol}^{-1}$ & $<10 \mathrm{~kJ} \mathrm{~mol}^{-1}$ & $<5 \mathrm{~kJ} \mathrm{~mol}^{-1}$ \\
\hline $\mathrm{dDR}$ & 2187 & 1070 & 1005 & 21 & 3 & 9 & 4 \\
\hline $\mathrm{DR}$ & 6561 & 2200 & 1916 & 27 & 6 & 8 & 3 \\
\hline $\mathrm{dDR} \alpha \mathrm{f}$ & 1620 & 149 & 117 & 27 & 8 & 16 & 4 \\
\hline $\mathrm{dDR} \beta \mathrm{f}$ & 1620 & 168 & 148 & 22 & 11 & 15 & 6 \\
\hline $\mathrm{DR} \alpha \mathrm{f}$ & 4860 & 238 & 201 & 40 & 13 & 24 & 13 \\
\hline $\mathrm{DR} \beta \mathrm{f}$ & 4860 & 311 & 266 & 25 & 13 & 18 & 11 \\
\hline $\mathrm{dDR} \alpha \mathrm{p}$ & 1026 & 121 & 105 & 5 & 4 & 11 & 4 \\
\hline $\mathrm{dDR} \beta \mathrm{p}$ & 1026 & 153 & 146 & 15 & 4 & 14 & 4 \\
\hline $\mathrm{DR} \alpha \mathrm{p}$ & 3078 & 243 & 188 & 21 & 8 & 24 & 9 \\
\hline $\mathrm{DR} \beta \mathrm{p}$ & 3078 & 310 & 272 & 14 & 5 & 18 & 9 \\
\hline
\end{tabular}

${ }^{a}$ First screening at B3LYP/6-31G computational level. ${ }^{b}$ Second screening with the employment of the 6-311++G(d,p) basis set.

$\alpha$-2-deoxy-D-ribofuranose, $\beta$-2-deoxy-D-ribofuranose, $\alpha$-D-ribofuranose, $\beta$-D-ribofuranose, $\alpha$-2-deoxy-D-ribopyranose, $\beta$-2-deoxy-D-ribopyranose, $\alpha$-D-ribopyranose, and $\beta$-D-ribopyranose, respectively.

A. Configurational Preference and Conformational Landscape of 2-Deoxy-D-ribose and D-Ribose in Aqueous Solution. A total of 1005 and 1916 unique minima were found for the open-chain forms of 2-deoxy-D-ribose and D-ribose, respectively, at $\mathrm{M} 06-2 \mathrm{X} / 6-311++\mathrm{G}(\mathrm{d}, \mathrm{p})$ computational level. In the furanose cases, 117, 148, 201, and 266 unique minima were obtained for $\alpha$-2-deoxy-D-ribofuranose, $\beta$-2-deoxy-D-ribofuranose, $\alpha$-D-ribofuranose, and $\beta$-D-ribofuranose, respectively. Finally, the number of unique minima for the pyranose forms is $105,146,188$, and 272 for $\alpha$-2-deoxy-Dribopyranose, $\beta$-2-deoxy-D-ribopyranose, $\alpha$-D-ribopyranose, and $\beta$-D-ribopyranose, in each case (see Table 1 ). As can be seen, the number of minima obtained in the cyclic conformations is much smaller than in the open-chain forms, due to the restrictions imposed by the ring. A similar number of minima is obtained when the B3LYP/6-311++G(d,p) computational level is used, except for the open-chain D-ribose where only 1664 minima are found, which is about 250 less than those obtained in the M06-2X/6-311++G(d,p) calculations (see Figure 4).

Figures 2 and 3 show the most stable conformers (less than $\left.3 \mathrm{~kJ} \mathrm{~mol}^{-1}\right)$ of the open-chain and pyranose $(\alpha$ - and $\beta$-) forms of 2-deoxy-D-ribose and D-ribose in PCM and PCM plus an explicit water molecule calculated at the M06-2X/6-311+ $+\mathrm{G}(\mathrm{d}, \mathrm{p})$ computational level. We can find this information for furanose $(\alpha$ - and $\beta$-) forms in the Supporting Information (Figure S1). In addition, the most stable conformers (less than $5 \mathrm{~kJ} \mathrm{~mol}^{-1}$ ) of the five forms of 2-deoxy-D-ribose and D-ribose in PCM-water calculated at the M06-2X/6-311++G(d,p) computational level are also gathered in the Supporting Information (see Figures S2, S3, and S4).

The most stable minimum of the open-chain 2-deoxy-Dribose exhibits a compact structure in the carbon skeleton, while the opposite happens in the second and third more stable minima. In the open-chain D-ribose, all the minima with a relative energy less than $5 \mathrm{~kJ} \mathrm{~mol}^{-1}$, present at least one of their $D_{\mathrm{CCCC}}$ with an s-trans configuration.

${ }^{2} \mathrm{~T}_{1}$ and ${ }^{2} \mathrm{E}$ conformations are found in the most stable minima of the $\alpha$-2-deoxy-D-ribofuranose, which are in the same Altona-Sundaralingam wheel zone. These ones favor the hydrogen bond $(\mathrm{HB})$ formation between the hydroxyl groups on the exo face. In half of the minima, the hydroxymethyl group points into the ring with the formation of a $\mathrm{HB}$ between its oxygen atom and the endo hydrogen atom bonded to C2.
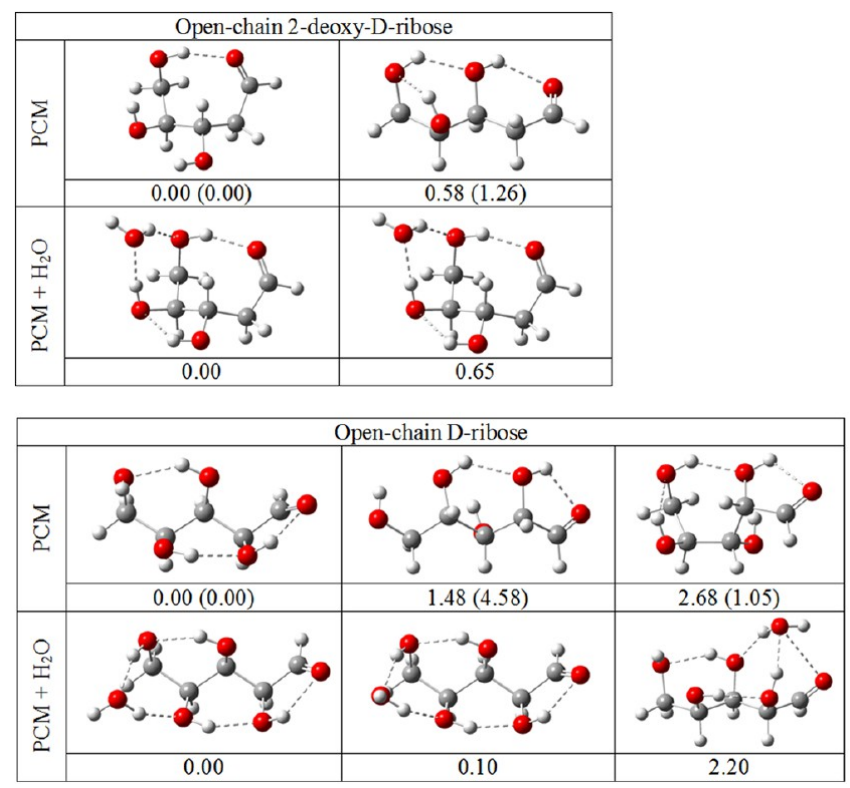

Figure 2. The most stable conformers (less than $3 \mathrm{~kJ} \mathrm{~mol}^{-1}$ ) of the open-chain forms of 2-deoxy-D-ribose and D-ribose in PCM and PCM plus an explicit water molecule calculated at the M06-2X/6-311+ $+\mathrm{G}(\mathrm{d}, \mathrm{p})$ computational level. Relative energies [MP2(full) results in parentheses] are in $\mathrm{kJ} \mathrm{mol}^{-1}$. The dashed lines indicate the noncovalent interactions obtained in the AIM analysis.

In $\beta$-2-deoxy-D-ribofuranose, ${ }^{4} \mathrm{E}$ predominates as ring conformation of the most stable minima with the appearance of an explicit $\mathrm{O} \cdots \mathrm{C} 2$ interaction, where the oxygen atom is part of the hydroxymethyl moiety. In addition, four ${ }^{1} \mathrm{~T}_{2}$ conformations are found with relative energies between 4.2 and $5.0 \mathrm{~kJ} \mathrm{~mol}^{-1}$. The ${ }^{2} \mathrm{~T}_{1^{-}}{ }^{2} \mathrm{E}$ and $\mathrm{E}_{2}{ }^{-1} \mathrm{~T}_{2}$ conformations are found in the most stable minima of the $\alpha$ - and $\beta$-D-ribofuranose, respectively. In some cases, a $\mathrm{HB}$ between the hydroxymethyl group and the endo hydrogen atom of $\mathrm{C} 2$ is found as in the case of the $\alpha-2$ deoxy-D-ribofuranose previously mentioned. Other low minima conformations found are the ${ }^{3} \mathrm{~T}_{4}$ and the ${ }^{4} \mathrm{E}-{ }^{4} \mathrm{~T}_{3}$ in the $\alpha$ - and $\beta$-D-ribofuranose, with relative energies between 3.57 and 4.98 $\mathrm{kJ} \mathrm{mol}^{-1}$, and 2.79 and $4.71 \mathrm{~kJ} \mathrm{~mol}^{-1}$, respectively.

Finally, regarding pyranose forms, the most stable minimum energy structures of $\alpha$-2-deoxy-D-ribopyranose present a ${ }^{4} C_{1}$ ring conformation, whereas that for $\beta$-2-deoxy-D-ribopyranose, it is ${ }^{1} \mathrm{C}_{4}$. For $\beta$-2-deoxy-D-ribopyranose the ${ }^{4} \mathrm{C}_{1}$ ring conformation appears in the fifth ranking position, with a relative energy of $6.39 \mathrm{~kJ} \mathrm{~mol}^{-1}(0.06 \%$ of the Boltzmann population taking into 
(a)

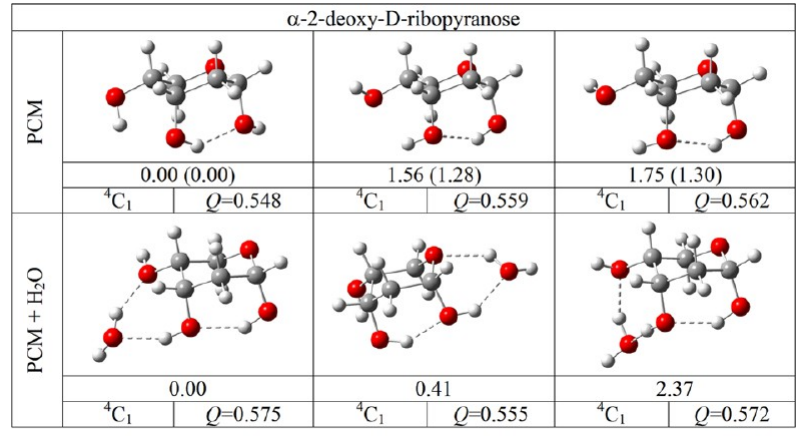

(c)

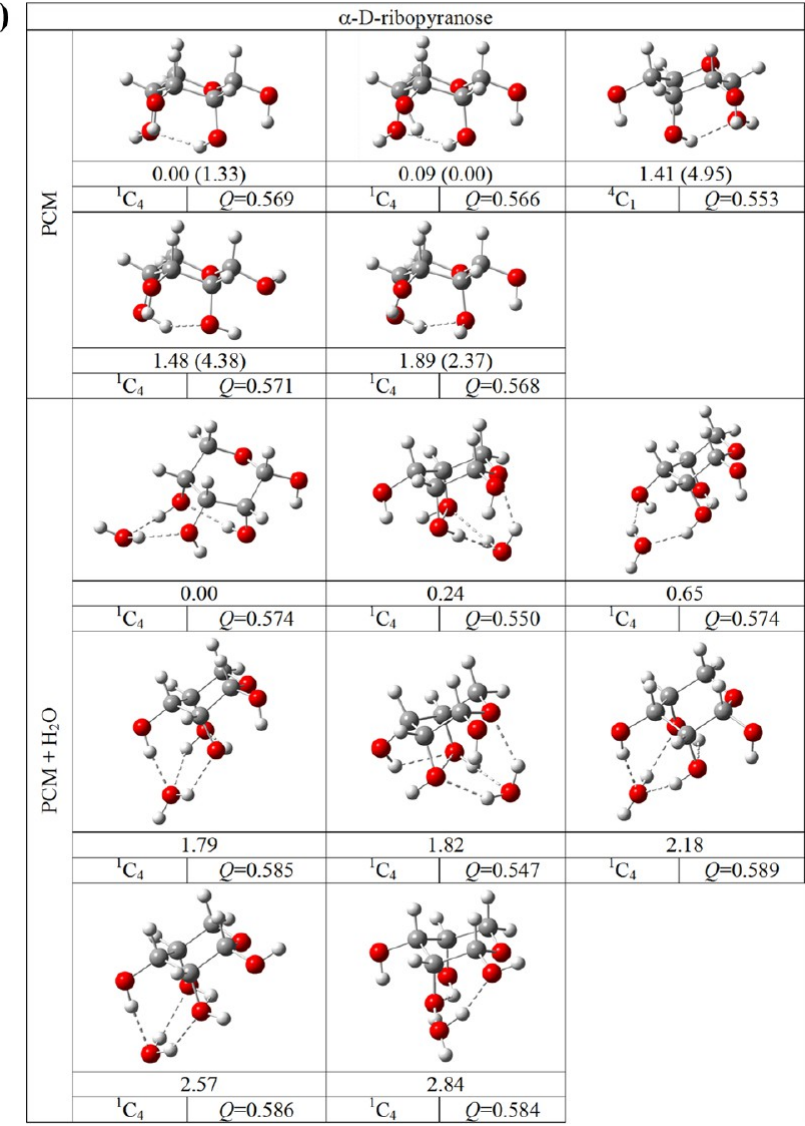

(b)

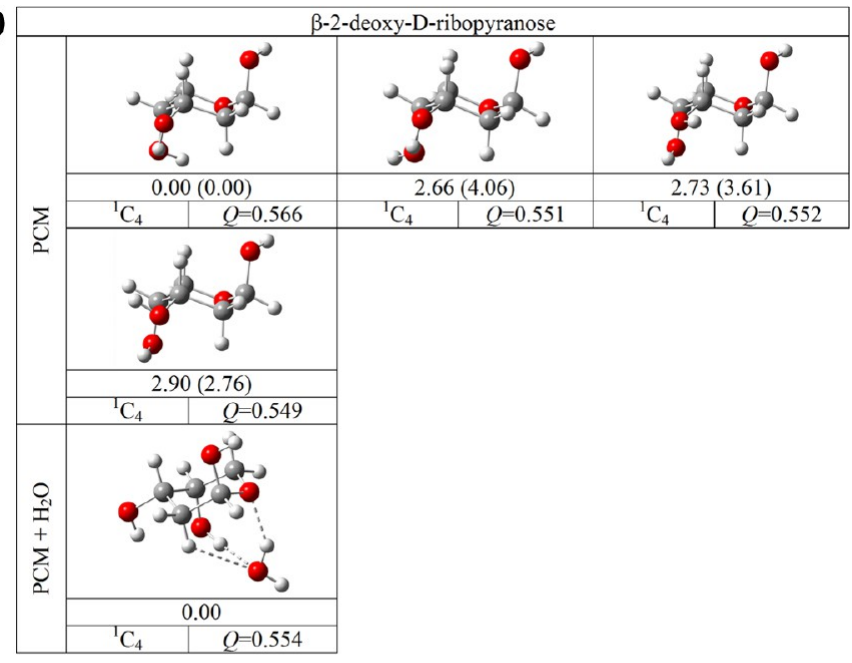

(d)

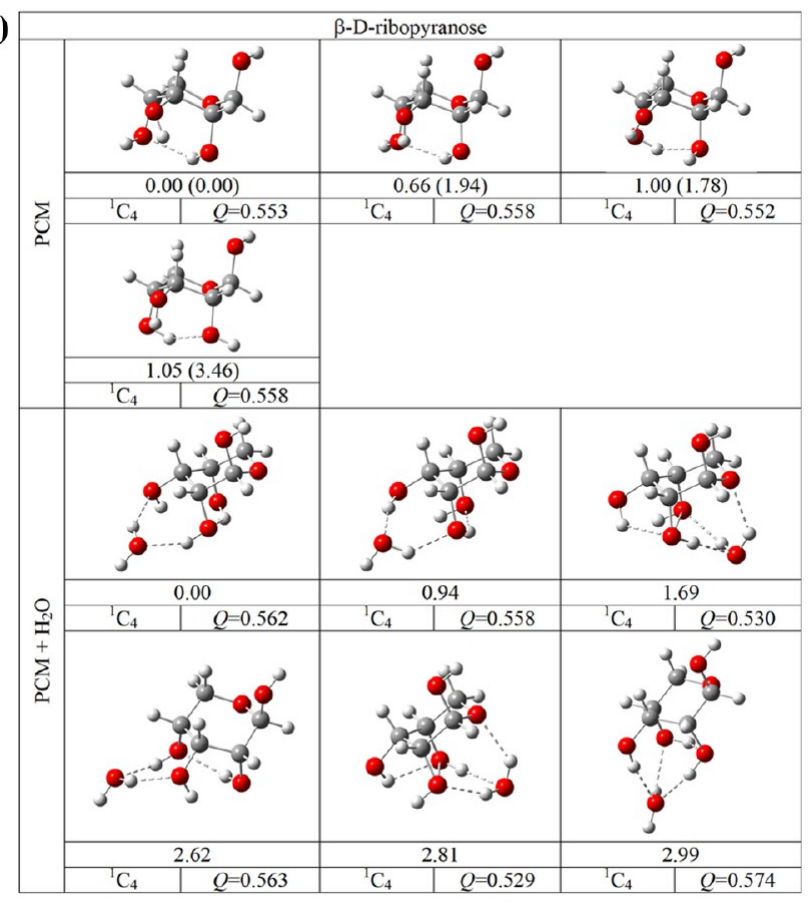

Figure 3. The most stable conformers (less than $\left.3 \mathrm{~kJ} \mathrm{~mol}^{-1}\right)$ of the pyranose $(\alpha$ - and $\beta$-) forms of 2-deoxy-D-ribose and D-ribose in PCM and PCM plus an explicit water molecule calculated at the M06-2X/6-311++G(d,p) computational level. Relative energies [MP2(full) results in parentheses] are in $\mathrm{kJ} \mathrm{mol}^{-1}$. Both the ring conformation $(C=$ chair, $H=$ half-chair, $S=$ skew, $B=$ boat and $E=$ envelope; superscript at the left refers to endo face; subscript at the right refers to exo face) and the $Q$ parameter in $\AA$ are included. The dashed lines indicate the noncovalent interactions obtained in the AIM analysis.

account all the conformers). In $\alpha$ - and $\beta$-D-ribopyranose the ${ }^{1} \mathrm{C}_{4}$ conformations are the most stable in both cases. It is very important to highlight that in all the most stable pyranose minima, only chair conformations are present with different orientations of the hydroxyl groups.

In the open-chain 2-deoxy-D-ribose, MP2 single point calculations agree with the energy ranking obtained at M062X computational level. However, at B3LYP level, the first M06-2X minimum becomes the fifth most stable conformer with a relative energy of $4.10 \mathrm{~kJ} \mathrm{~mol}^{-1}$ (see Table 2 and a more detailed table in the Supporting Information). In the openchain D-ribose, MP2 single point calculations follow the M06$2 \mathrm{X}$ order, with the exception of the second and third structures which are inverted at MP2 level. B3LYP results provide the same ranking of the M06-2X calculations only for the first and second minima, while the rest of the most stable ones are disordered.

In the case of the furanose configurations, the energy ranking is different for the three methods considered. Only in the $\alpha$-2deoxy-D-ribofuranose is the most stable minimum the same at M06-2X and MP2 levels. In the rest of furanose conformers, the most stable minimum at M06-2X corresponds to the second, third and fifth place, for $\beta$-2-deoxy-D-ribofuranose, $\alpha$-Dribofuranose, and $\beta$-D-ribofuranose, respectively, at MP2 level.

In contrast, the pyranose minima show, in general, good consistence between the different methodologies employed. For instance, in $\alpha$-2-deoxy-D-ribopyranose and $\beta$-D-ribopyranose, the energy ranking is the same for the DFT and MP2 calculations, with the exception of the second and third minima of $\beta$-D-ribopyranose which are alternated at MP2 level. 

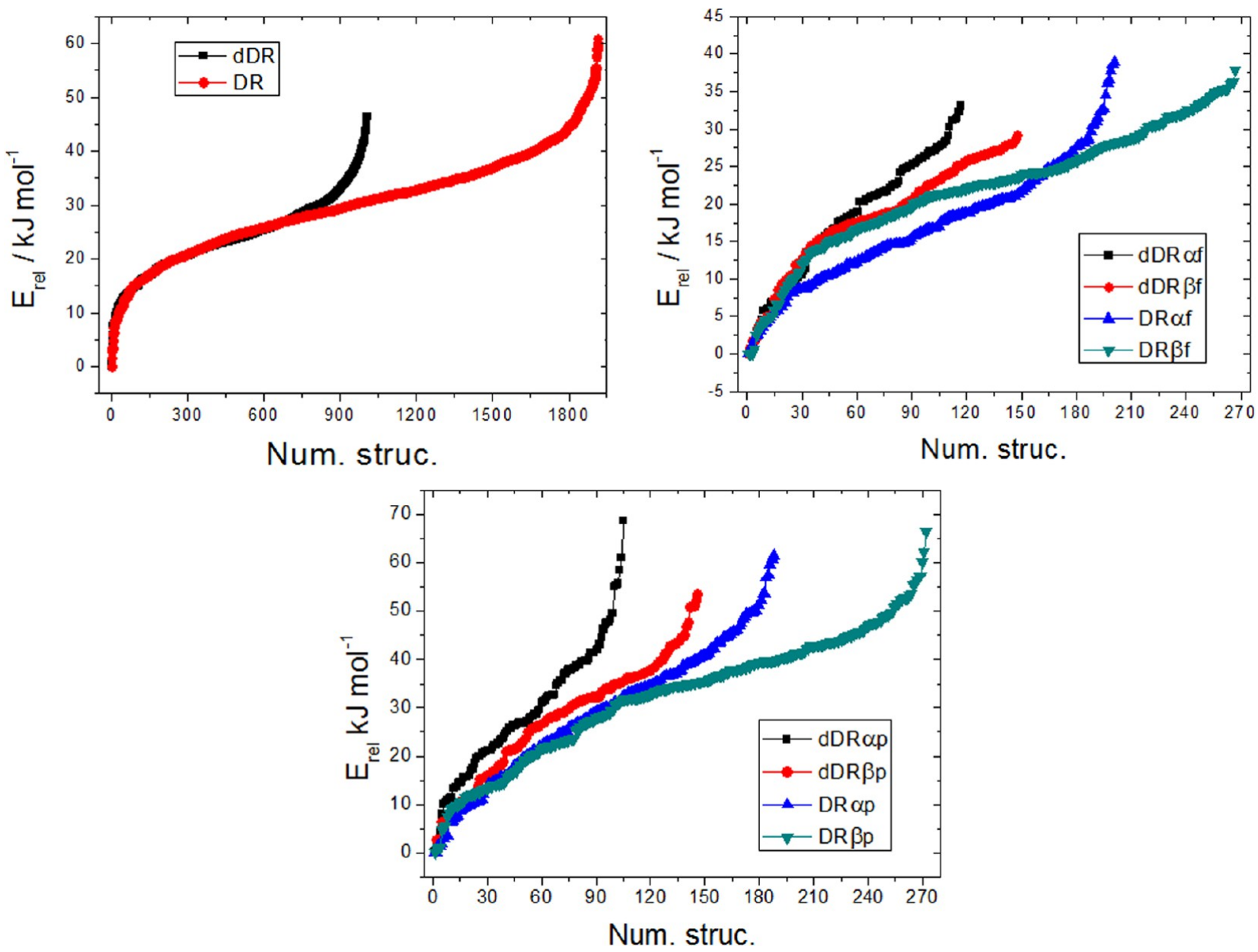

Figure 4. Left to right and top to bottom: variation of all open-chain, furanose, and pyranose conformations of 2-deoxy-D-ribose and D-ribose according to the M06-2X/6-311++G(d,p) relative energy to their respective global minima.

In $\beta$-2-deoxy-D-ribopyranose and $\alpha$-D-ribopyranose the first minimum coincides for both DFT functionals and the ranking of the most stable minima does not show important differences. However, MP2 calculations for $\alpha$-D-ribopyranose have less similarity to those obtained at the DFT levels.

The population of the different configurations for the 2-deoxy-D-ribose and D-ribose using all the minima obtained at the DFT levels are gathered in Table 3. Analogous population results are obtained at M06-2X and MP2 levels. In the two molecules studied, the $\alpha$-pyranose conformers are the most populated, followed by the $\beta$-pyranose ones. Only B3LYP results indicate the presence of significant populations of openchain and furanose forms. Besides, Barnett et al. ${ }^{58}$ analyzed the furanose ( $\beta$-D-ribofuranose) and pyranose ( $\beta$-D-glucopyranose) free energy pucker surfaces and volumes in water solutions using AM1, PM3, PM3CARB-1, and SCC-DFTB semiempirical potentials. A comparison with DFT optimized structures and at Hartree-Fock (HF) free energy surface revealed that SCC-DFTB provided the best semiempirical description of five- and six-membered carbohydrate ring deformation. Also, Dowd et al. ${ }^{59}$ carried out a MM3 modeling of D-ribose and 2-deoxy-D-ribose ring puckering with an implicit solvation model in order to simulate the solvent effects. They concluded from experimental and theoretical results that several tautomeric forms of the two monosaccharides exist in multiple conformations in solution. The authors pointed out that the discrepancies between their calculated energies and the free energies derived from NMR results were less than $1.0 \mathrm{kcal} \mathrm{mol}^{-1}$, concluding that the equilibrium between conformers was not very accurately predicted. Finally, it seems that the M06-2X functional is a good choice for the system under study. Although, the M06-2X functional is more computationally demanding than the B3LYP functional, while less than MP2, it performs well as it predicts structures, energies, and harmonic spectra quite accurately. ${ }^{60}$

2. AIM and NBO Analysis of the Intramolecular Weak Interactions. Atoms in Molecules (AIM) ${ }^{43,44}$ and Natural Bond Orbital $(\mathrm{NBO})^{51}$ methodologies provide a set of interesting tools for the analysis of the intramolecular weak interactions.

The main group of weak interactions which take place in the 2-deoxy-D-ribose and D-ribose carbohydrates studied in the present work is the hydrogen bonds (HB).

The topological approach of AIM establishes that an HB is characterized by the presence of a bond critical point (BCP) which, through a bond path, links to nuclear attractors: one hydrogen atomic center and on electronegative (oxygen) atomic center. The electron density and its Laplacian at BCP present positive but small values compared, in absolute terms, to those computed for covalent bonds. The orbital approach of NBO indicates that a $\mathrm{HB}$ is associated to the charge transfer between a lone pair (LP) on the acceptor moiety and the $\sigma^{*}$ (antibonding) orbital of the donor moiety which includes the hydrogen atom.

The types of HB formed between two hydroxyl groups and even between one hydroxyl group and the aldehyde moiety in the case of the open-chain forms, can be grouped using the 
Table 2. Relative Energy in $\mathrm{kJ} \mathrm{mol}^{-1}$ and Boltzmann Population in Percentage for the Most Stable Minima (Restricted for Conformers with Energies Less than $\left.5 \mathrm{~kJ} \mathrm{~mol}^{-1}\right)^{a}$ of 2-Deoxy-D-ribose and D-Ribose (Open-Chain, Furanose, and Pyranose Forms) at the M06-2X/6-311++G(d,p) and MP2(full)/6-311++G(3df,2p)//M06-2X/6-311++G(d,p) Computational Levels $(T=298.16 \mathrm{~K})$

\begin{tabular}{|c|c|c|c|c|c|c|c|}
\hline \multirow{3}{*}{ Structure } & \multicolumn{2}{|c|}{$\begin{array}{l}\text { PCM M06-2X/ } \\
6-311++G(d, p)\end{array}$} & \multicolumn{2}{|c|}{$\begin{array}{c}\text { PCM MP2 } \\
(\text { full }) / 6-311+ \\
+(3 \mathrm{df}, 2 \mathrm{p}) / / \\
\text { M06-2X/6-311 } \\
++\mathrm{G}(\mathrm{d}, \mathrm{p}) / /\end{array}$} & \multicolumn{3}{|c|}{$\begin{array}{c}\mathrm{PCM}+\text { explicit } \mathrm{H}_{2} \mathrm{O} \text { M06- } \\
2 \mathrm{X} / 6-311++\mathrm{G}(\mathrm{d}, \mathrm{p})\end{array}$} \\
\hline & $\Delta E_{0}$ & \% Pop. & $\Delta E_{0}$ & \% Pop. & Structure & $\Delta E_{0}$ & \% Pop. \\
\hline & & & Open-Cl & in 2-Deoxy-1 & -D-ribose & & \\
\hline dDR01 & 0.00 & 50.6 & 0.00 & 59.6 & dDR-w01 & 0.00 & 47.3 \\
\hline dDR02 & 0.58 & 40.0 & 1.26 & 35.8 & dDR-w02 & 0.65 & 36.4 \\
\hline \multirow[t]{3}{*}{ dDR03 } & 4.16 & 9.4 & 6.34 & 4.6 & dDR-w03 & 4.24 & 8.5 \\
\hline & & & & & dDR-w04 & 4.47 & 7.8 \\
\hline & \multicolumn{7}{|c|}{ Open-Chain D-Ribose } \\
\hline DR01 & 0.00 & 39.4 & 0.00 & 47.0 & DR-w01 & 0.00 & 42.2 \\
\hline DR02 & 1.48 & 21.7 & 4.58 & 7.4 & DR-w02 & 0.10 & 40.5 \\
\hline DR03 & 2.68 & 13.3 & 1.05 & 30.8 & DR-w03 & 2.20 & 17.3 \\
\hline DR04 & 3.32 & 10.3 & 5.27 & 5.6 & & & \\
\hline DR05 & 3.50 & 9.6 & 5.47 & 5.2 & & & \\
\hline DR06 & 4.77 & 5.7 & 6.12 & 4.0 & & & \\
\hline \multirow{3}{*}{ Structure } & \multicolumn{4}{|c|}{$\begin{array}{c}\text { PCM MP2(full)/ } \\
6-311++(3 \mathrm{df}, 2 \mathrm{p}) / / \\
\text { M06-2X/ } \\
6-311++G(d, p) / /\end{array}$} & \multicolumn{3}{|c|}{$\begin{array}{c}\text { PCM + explicit } \mathrm{H}_{2} \mathrm{O} \text { M06- } \\
2 \mathrm{X} / 6-311++\mathrm{G}(\mathrm{d}, \mathrm{p})\end{array}$} \\
\hline & $\Delta E_{0}$ & \% Pop. & $\Delta E_{0}$ & \% Pop. & Structure & $\Delta E_{0}$ & \% Pop. \\
\hline & \multicolumn{7}{|c|}{$\alpha$-2-Deoxy-D-ribofuranose } \\
\hline $\mathrm{dDR} \alpha \mathrm{f01}$ & 0.00 & 20.8 & 0.00 & 25.8 & $\mathrm{dDR} \alpha \mathrm{f}-\mathrm{w} 01$ & 0.00 & 39.1 \\
\hline $\mathrm{dDR} \alpha \mathrm{f02}$ & 0.13 & 19.8 & 2.70 & 8.7 & $\mathrm{dDR} \alpha \mathrm{f}-\mathrm{w} 02$ & 0.42 & 33.0 \\
\hline $\mathrm{dDR} \alpha \mathrm{f} 03$ & 0.16 & 19.5 & 0.54 & 20.8 & dDR $\alpha f-w 03$ & 1.54 & 21.0 \\
\hline $\mathrm{dDR} \alpha \mathrm{f0} 4$ & 0.56 & 16.6 & 0.86 & 18.2 & dDR $\alpha f-w 04$ & 4.30 & 6.9 \\
\hline $\mathrm{dDR} \alpha \mathrm{f} 05$ & 2.33 & 8.1 & 2.69 & 8.7 & & & \\
\hline $\mathrm{dDR} \alpha \mathrm{f06}$ & 3.04 & 6.1 & 1.98 & 11.6 & & & \\
\hline $\mathrm{dDR} \alpha \mathrm{f} 07$ & 3.17 & 5.8 & 5.07 & 3.3 & & & \\
\hline \multirow[t]{2}{*}{$\mathrm{dDR} \alpha \mathrm{f} 08$} & 4.57 & 3.3 & 5.40 & 2.9 & & & \\
\hline & \multicolumn{7}{|c|}{$\beta$-2-Deoxy-D-ribofuranose } \\
\hline $\mathrm{dDR} / \mathrm{f} 01$ & 0.00 & 23.5 & 0.64 & 18.7 & $\mathrm{dDR} / \mathrm{f}-\mathrm{w} 01$ & 0.00 & 46.7 \\
\hline $\mathrm{dDR} / \mathrm{f} 02$ & 0.79 & 17.1 & 0.00 & 24.2 & $\mathrm{dDR} \beta \mathrm{f}-\mathrm{w} 02$ & 1.65 & 24.0 \\
\hline $\mathrm{dDR} / \mathrm{f} 03$ & 1.70 & 11.8 & 3.55 & 5.8 & $\mathrm{dDR} / \mathrm{f}-\mathrm{w} 03$ & 4.36 & 8.1 \\
\hline $\mathrm{dDR} / \mathrm{f} 04$ & 1.80 & 11.4 & 2.32 & 9.5 & $\mathrm{dDR} / \mathrm{f}-\mathrm{w} 04$ & 4.60 & 7.3 \\
\hline $\mathrm{dDR} \beta \mathrm{f05}$ & 1.89 & 11.0 & 1.81 & 11.7 & $\mathrm{dDR} \beta \mathrm{f}-\mathrm{w} 05$ & 4.65 & 7.1 \\
\hline $\mathrm{dDR} / \mathrm{f} 06$ & 3.39 & 6.0 & 1.55 & 13.0 & $\mathrm{dDR} / \mathrm{f}-\mathrm{w} 06$ & 4.76 & 6.8 \\
\hline $\mathrm{dDR} / \mathrm{f} 07$ & 4.19 & 4.3 & 3.79 & 5.3 & & & \\
\hline $\mathrm{dDR} / \mathrm{f08}$ & 4.23 & 4.3 & 4.73 & 3.6 & & & \\
\hline $\mathrm{dDR} / \mathrm{f09}$ & 4.44 & 3.9 & 6.46 & 1.8 & & & \\
\hline $\mathrm{dDR} / \mathrm{f} 10$ & 4.65 & 3.6 & 3.98 & 4.9 & & & \\
\hline \multirow[t]{2}{*}{$\mathrm{dDR} / \mathrm{f} 11$} & 4.99 & 3.1 & 6.66 & 1.5 & & & \\
\hline & \multicolumn{7}{|c|}{$\alpha$-D-Ribofuranose } \\
\hline $\mathrm{DR} \alpha \mathrm{f} 01$ & 0.00 & 20.5 & 0.92 & 21.9 & $\mathrm{DR} \alpha \mathrm{f}-\mathrm{w} 01$ & 0.00 & 19.0 \\
\hline $\mathrm{DR} \alpha \mathrm{f02}$ & 0.87 & 14.5 & 4.11 & 6.0 & $\mathrm{DR} \alpha \mathrm{f}-\mathrm{w} 02$ & 0.23 & 17.3 \\
\hline $\mathrm{DR} \alpha \mathrm{f03}$ & 1.21 & 12.6 & 0.00 & 31.8 & $\mathrm{DR} \alpha \mathrm{f}-\mathrm{w} 03$ & 0.63 & 14.7 \\
\hline $\mathrm{DR} \alpha \mathrm{f04}$ & 2.07 & 8.9 & 3.37 & 8.2 & $\mathrm{DR} \alpha \mathrm{f}-\mathrm{w} 04$ & 2.27 & 7.6 \\
\hline $\mathrm{DR} \alpha \mathrm{f05}$ & 2.47 & 7.6 & 3.44 & 7.9 & $\mathrm{DR} \alpha \mathrm{f}-\mathrm{w} 05$ & 2.41 & 7.2 \\
\hline $\mathrm{DR} \alpha \mathrm{f06}$ & 2.64 & 7.1 & 6.70 & 2.1 & $\mathrm{DR} \alpha \mathrm{f}-\mathrm{w} 06$ & 2.51 & 6.9 \\
\hline $\mathrm{DR} \alpha \mathrm{f07}$ & 3.04 & 6.0 & 5.34 & 3.7 & $\mathrm{DR} \alpha \mathrm{f}-\mathrm{w} 07$ & 2.74 & 6.3 \\
\hline $\mathrm{DR} \alpha \mathrm{f0} 8$ & 3.57 & 4.9 & 6.22 & 2.6 & DR $\alpha \mathrm{f}-\mathrm{w} 08$ & 3.59 & 4.5 \\
\hline $\mathrm{DR} \alpha \mathrm{f09}$ & 3.63 & 4.7 & 3.91 & 6.5 & DR $\alpha$ f-w09 & 3.81 & 4.1 \\
\hline $\mathrm{DR} \alpha \mathrm{f} 10$ & 4.22 & 3.7 & 5.59 & 3.3 & DR $\alpha \mathrm{f}-\mathrm{w} 10$ & 4.06 & 3.7 \\
\hline $\mathrm{DR} \alpha \mathrm{f} 11$ & 4.30 & 3.6 & 7.12 & 1.8 & $\mathrm{DR} \alpha \mathrm{f}-\mathrm{w} 11$ & 4.44 & 3.2 \\
\hline $\mathrm{DR} \alpha \mathrm{f} 12$ & 4.67 & 3.1 & 5.68 & 3.2 & $\mathrm{DR} \alpha \mathrm{f}-\mathrm{w} 12$ & 4.64 & 2.9 \\
\hline $\mathrm{DR} \alpha \mathrm{f} 13$ & 4.98 & 2.8 & 8.47 & 1.0 & DR $\alpha f-w 13$ & 4.98 & 2.6 \\
\hline
\end{tabular}

\begin{tabular}{|c|c|c|c|c|c|c|c|}
\hline \multirow[b]{2}{*}{ Structure } & \multicolumn{4}{|c|}{$\begin{array}{c}\text { PCM MP2(full)/ } \\
6-311++(3 \mathrm{df}, 2 \mathrm{p}) / / \\
\text { M06-2X/ } \\
6-311++G(\mathrm{~d}, \mathrm{p}) / /\end{array}$} & \multicolumn{3}{|c|}{$\begin{array}{c}\text { PCM + explicit } \mathrm{H}_{2} \mathrm{O} \text { M06 } \\
2 \mathrm{X} / 6-311++\mathrm{G}(\mathrm{d}, \mathrm{p})\end{array}$} \\
\hline & $\Delta E_{0}$ & \% Pop. & $\Delta E_{0}$ & \% Pop. & Structure & $\Delta E_{0}$ & \% Pop. \\
\hline & \multicolumn{7}{|c|}{$\beta$-D-Ribofuranose } \\
\hline $\mathrm{DR} / \mathrm{f} 01$ & 0.00 & 20.7 & 1.68 & 9.3 & $\mathrm{DR} / \mathrm{f}-\mathrm{w} 01$ & 0.00 & 23.1 \\
\hline $\mathrm{DR} / \mathrm{f0} 2$ & 0.03 & 20.5 & 1.00 & 12.3 & $\mathrm{DR} \beta \mathrm{f}-\mathrm{w} 02$ & 0.70 & 17.5 \\
\hline $\mathrm{DR} / \mathrm{f03}$ & 0.69 & 15.7 & 0.07 & 17.9 & $\mathrm{DR} / \mathrm{f}-\mathrm{w} 03$ & 0.72 & 17.3 \\
\hline $\mathrm{DR} / \mathrm{f0} 4$ & 2.45 & 7.7 & 0.00 & 18.4 & $\mathrm{DR} \beta \mathrm{f}-\mathrm{w} 04$ & 1.29 & 13.8 \\
\hline $\mathrm{DR} / \mathrm{f05}$ & 3.00 & 6.2 & 2.80 & 5.9 & $\mathrm{DR} / \mathrm{f}-\mathrm{w} 05$ & 4.02 & 4.6 \\
\hline $\mathrm{DR} / \mathrm{f06}$ & 3.40 & 5.3 & 0.83 & 13.2 & $\mathrm{DR} / \mathrm{f}-\mathrm{w} 06$ & 4.11 & 4.4 \\
\hline $\mathrm{DR} \beta \mathrm{f} 07$ & 3.74 & 4.6 & 2.79 & 6.0 & $\mathrm{DR} / \mathrm{f}-\mathrm{w} 07$ & 4.12 & 4.4 \\
\hline $\mathrm{DR} \beta \mathrm{f0} 8$ & 4.21 & 3.8 & 4.48 & 3.0 & DR $\beta$ f-w08 & 4.20 & 4.2 \\
\hline DR $\beta$ f09 & 4.42 & 3.5 & 3.19 & 5.1 & DR $\beta$ f-w09 & 4.53 & 3.7 \\
\hline $\mathrm{DR} \beta \mathrm{f} 10$ & 4.46 & 3.4 & 5.93 & 1.7 & DR $\beta \mathrm{f}-\mathrm{w} 10$ & 4.54 & 3.7 \\
\hline $\mathrm{DR} \beta \mathrm{f} 11$ & 4.75 & 3.0 & 7.38 & 0.9 & $\mathrm{DR} / \mathrm{f}-\mathrm{w} 11$ & 4.82 & 3.3 \\
\hline $\mathrm{DR} \beta \mathrm{f} 12$ & 4.96 & 2.8 & 4.01 & 3.6 & & & \\
\hline $\mathrm{DR} / \mathrm{f} 13$ & 4.99 & 2.8 & 4.71 & 2.7 & & & \\
\hline \multirow{3}{*}{ Structure } & \multicolumn{4}{|c|}{$\begin{array}{c}\text { PCM MP2(full)/ } \\
6-311++(3 \mathrm{df}, 2 \mathrm{p}) / / \\
\text { M06-2X/ } \\
6-311++G(d, p) / /\end{array}$} & \multicolumn{3}{|c|}{$\begin{array}{c}\mathrm{PCM}+\text { explicit } \mathrm{H}_{2} \mathrm{O} \text { M06- } \\
2 \mathrm{X} / 6-311++\mathrm{G}(\mathrm{d}, \mathrm{p})\end{array}$} \\
\hline & $\Delta E_{0}$ & \% Pop. & $\Delta E_{0}$ & $\%$ Pop. & Structure & $\Delta E_{0}$ & \% Pop. \\
\hline & \multicolumn{7}{|c|}{$\alpha$-2-Deoxy-D-ribopyranose } \\
\hline $\mathrm{dDR} \alpha \mathrm{p} 01$ & 0.00 & 45.7 & 0.00 & 40.5 & $\mathrm{dDR} \alpha \mathrm{p}-\mathrm{w} 01$ & 0.00 & 40.7 \\
\hline $\mathrm{dDR} \alpha \mathrm{p} 02$ & 1.56 & 24.3 & 1.28 & 24.2 & $\mathrm{dDR} \alpha \mathrm{p}-\mathrm{w} 02$ & 0.41 & 34.5 \\
\hline $\mathrm{dDR} \alpha \mathrm{p} 03$ & 1.75 & 22.6 & 1.30 & 24.0 & $\mathrm{dDR} \alpha \mathrm{p}-\mathrm{w} 03$ & 2.37 & 15.6 \\
\hline \multirow[t]{2}{*}{$\mathrm{dDR} \alpha \mathrm{p} 04$} & 4.50 & 7.4 & 3.17 & 11.3 & $\mathrm{dDR} \alpha \mathrm{p}-\mathrm{w} 04$ & 3.70 & 9.2 \\
\hline & \multicolumn{7}{|c|}{$\beta$-2-Deoxy-D-ribopyranose } \\
\hline $\mathrm{dDR} \beta \mathrm{p} 01$ & 0.00 & 50.5 & 0.00 & 56.9 & $\mathrm{dDR} \beta \mathrm{p}-\mathrm{w} 01$ & 0.00 & 67.5 \\
\hline $\mathrm{dDR} \beta \mathrm{p} 02$ & 2.66 & 17.2 & 4.06 & 11.1 & $\mathrm{dDR} \beta \mathrm{p}-\mathrm{w} 02$ & 4.41 & 11.4 \\
\hline $\mathrm{dDR} \beta \mathrm{p} 03$ & 2.73 & 16.7 & 3.61 & 13.3 & $\mathrm{dDR} \beta \mathrm{p}-\mathrm{w} 03$ & 4.41 & 11.4 \\
\hline \multirow[t]{2}{*}{$\mathrm{dDR} \beta \mathrm{p} 04$} & 2.90 & 15.6 & 2.76 & 18.7 & $\mathrm{dDR} \beta \mathrm{p}-\mathrm{w} 04$ & 4.79 & 9.7 \\
\hline & \multicolumn{7}{|c|}{$\alpha$-D-Ribopyranose } \\
\hline $\mathrm{DR} \alpha \mathrm{p} 01$ & 0.00 & 23.0 & 1.33 & 22.7 & DR $\alpha$ p-w01 & 0.00 & 20.5 \\
\hline $\mathrm{DR} \alpha \mathrm{p} 02$ & 0.09 & 22.2 & 0.00 & 38.8 & DR $\alpha$ p-w02 & 0.24 & 18.6 \\
\hline $\mathrm{DR} \alpha \mathrm{p} 03$ & 1.41 & 13.0 & 4.95 & 5.3 & DR $\alpha$ p-w03 & 0.65 & 15.7 \\
\hline $\mathrm{DR} \alpha \mathrm{p} 04$ & 1.48 & 12.7 & 4.38 & 6.6 & DR $\alpha$ p-w04 & 1.79 & 9.9 \\
\hline $\mathrm{DR} \alpha \mathrm{p} 05$ & 1.89 & 10.7 & 2.37 & 14.9 & DR $\alpha$ p-w05 & 1.82 & 9.8 \\
\hline $\mathrm{DR} \alpha \mathrm{p} 06$ & 3.03 & 6.8 & 4.69 & 5.8 & DR $\alpha$ p-w06 & 2.18 & 8.5 \\
\hline $\mathrm{DR} \alpha \mathrm{p} 07$ & 3.34 & 6.0 & 6.73 & 2.6 & DR $\alpha$ p-w07 & 2.57 & 7.3 \\
\hline \multirow[t]{3}{*}{$\mathrm{DR} \alpha \mathrm{p} 08$} & 3.53 & 5.6 & 6.09 & 3.3 & DR $\alpha$ p-w08 & 2.84 & 6.5 \\
\hline & & & & & DR $\alpha$ p-w09 & 4.61 & 3.2 \\
\hline & \multicolumn{7}{|c|}{$\beta$-D-Ribopyranose } \\
\hline $\mathrm{DR} \beta \mathrm{p} 01$ & 0.00 & 30.9 & 0.00 & 45.0 & $\mathrm{DR} \beta \mathrm{p}-\mathrm{w} 01$ & 0.00 & 26.6 \\
\hline $\mathrm{DR} \beta \mathrm{p} 02$ & 0.66 & 23.6 & 1.94 & 20.6 & $\mathrm{DR} \beta \mathrm{p}-\mathrm{w} 02$ & 0.94 & 18.2 \\
\hline $\mathrm{DR} \beta \mathrm{p} 03$ & 1.00 & 20.6 & 1.78 & 22.0 & $\mathrm{DR} \beta \mathrm{p}-\mathrm{w} 03$ & 1.69 & 13.4 \\
\hline $\mathrm{DR} \beta \mathrm{p} 04$ & 1.05 & 20.2 & 3.46 & 11.1 & $\mathrm{DR} \beta \mathrm{p}-\mathrm{w} 04$ & 2.62 & 9.2 \\
\hline \multirow[t]{5}{*}{$\mathrm{DR} \beta \mathrm{p} 05$} & 4.69 & 4.7 & 8.73 & 1.3 & $\mathrm{DR} \beta \mathrm{p}-\mathrm{w} 05$ & 2.81 & 8.5 \\
\hline & & & & & DR $\beta$ p-w06 & 2.99 & 7.9 \\
\hline & & & & & $\mathrm{DR} \beta \mathrm{p}-\mathrm{w} 07$ & 3.40 & 6.7 \\
\hline & & & & & $\mathrm{DR} \beta \mathrm{p}-\mathrm{w} 08$ & 3.71 & 5.9 \\
\hline & & & & & $\mathrm{DR} \beta \mathrm{p}-\mathrm{w} 09$ & 4.95 & 3.6 \\
\hline
\end{tabular}

${ }^{a} K=-R T \ln \Delta E_{0}$, where $K$ is the population relationship, $R$ the ideal gas constant, $T$ the absolute temperature, and $\Delta E_{0}$ the relative energy. 
Table 3. Boltzmann Population ${ }^{a}$ in Percentage for 2-Deoxy-D-ribose and D-Ribose at the M06-2X/6-311++G(d,p) and MP2(full)/6-311++G(3df,2p)//M06-2X/6-311++G(d,p) Computational Levels ${ }^{b}$

\begin{tabular}{|c|c|c|c|c|c|c|c|c|c|c|c|c|c|c|c|}
\hline \multirow[b]{2}{*}{ structure } & \multicolumn{5}{|c|}{ PCM/M06-2X } & \multicolumn{5}{|c|}{$\mathrm{MP2}^{c}$} & \multicolumn{5}{|c|}{$\left(\mathrm{PCM}+\mathrm{H}_{2} \mathrm{O}\right) / \mathrm{M} 06-2 \mathrm{X}^{d}$} \\
\hline & open & $\alpha$-fur & $\beta$-fur & $\alpha$-pyr & $\beta$-pyr & open & $\alpha$-fur & $\beta$-fur & $\alpha$-pyr & $\beta$-pyr & open & $\alpha$-fur & $\beta$-fur & $\alpha$-pyr & $\beta$-pyr \\
\hline 2-deoxy-D-ribose & 0.0 & 0.6 & 0.3 & 86.6 & 12.5 & 0.0 & 0.6 & 0.1 & 91.3 & 8.0 & 0.0 & 1.4 & 0.4 & 73.4 & 24.8 \\
\hline D-ribose & 0.0 & 0.1 & 0.1 & 71.0 & 28.8 & 0.0 & 0.1 & 0.0 & 71.6 & 28.3 & 0.0 & 0.1 & 0.1 & 69.2 & 30.6 \\
\hline
\end{tabular}

${ }^{a} K=-R T \ln \Delta E_{0}$, where $K$ is the population relationship, $R$ the ideal gas constant, $T$ the absolute temperature, and $\Delta E_{0}$ the relative energy. ${ }^{b}$ Calculations take into account all minima $(T=298.16 \mathrm{~K})$ for every configuration. ${ }^{c}$ In the case of MP2(full) calculations, only for the most stable minima, i.e., with relative M06-2X energies less than $5 \mathrm{~kJ} \mathrm{~mol}^{-1} \cdot{ }^{d}\left(\mathrm{PCM}+\mathrm{H}_{2} \mathrm{O}\right) / \mathrm{M} 06-2 \mathrm{X}$ calculations: an explicit molecule of water was added to those minima in PCM with relative energy less than $3 \mathrm{~kJ} \mathrm{~mol}^{-1}$.

profile of the electron density, $\rho$, its Laplacian, $\nabla^{2} \rho$, and the second-order perturbation NBO energy, $E^{(2)}$, versus the geometrical distance attending to the number of skeleton carbon atoms which separate the interacting functional groups (Scheme 1). ${ }^{1}$ Thus, the interactions present in these

Scheme 1. HB Type Interactions in 2-Deoxy-D-ribose and D-Ribose: (a) 1-2, (b) 1-3, (c) 1-4, and (d) 1-5

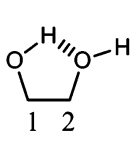

(a)

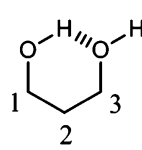

(b)

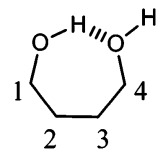

(c)

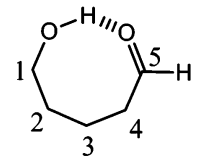

(d) compounds can be classified a priori as: $1-2,1-3,1-4$, and $1-5$ type interactions.

As can be seen in Figure 5, for all minima in 2-deoxy-D-ribose and D-ribose with total relative energy less than $10 \mathrm{~kJ} \mathrm{~mol}^{-1}$, the electron density at BCP $(a)$, its Laplacian $(b)$, and $E^{(2)}$ NBO energy $(c)$, exhibit exponential relationships versus the $\mathrm{O} \cdots \mathrm{H}$ interatomic distance, in agreement with previous reports. ${ }^{61-63}$ In all of them, the type of interaction can be classified, specially using $\nabla^{2} \rho_{\mathrm{O} \ldots \mathrm{H}}$, in three main groups the $1-2$ (pseudofive membered ring), 1-3 (pseudosix membered ring), and 1-4 plus 1-5 (pseudoseven and pseudoeight membered rings). Additionally, a relationship is observed between $E^{(2)} \mathrm{NBO}$ energy versus the electron density $(\rho)$, establishing a correlation between a topological and an orbital variables.

1-2 type interactions present a smaller range of values than $1-3$ or $1-4$ ones in the geometrical and even in the topological and orbital parameters. 1-2 type interactions range between 1.89 and $2.14 \AA$, 113 and $121 \mathrm{deg}, 0.020$ and 0.029 au for the electron density, and 0.088 and 0.134 au for its Laplacian, and finally, 5.23 and $16.78 \mathrm{~kJ} \mathrm{~mol}^{-1}$ for $E^{(2)}$. Furthermore, $1-3$ type interactions are between 1.87 and $2.28 \AA$, 123 and 144 deg, 0.014 and 0.031 au for the electron density, and 0.053 and 0.118 au for its Laplacian, and finally, 2.51 and $45.02 \mathrm{~kJ} \mathrm{~mol}^{-1}$ for $E^{(2)}$. In $1-4$ type interactions the intervals increase with respect to this last one, being the upper limit in $E^{(2)}, 72.34 \mathrm{~kJ} \mathrm{~mol}^{-1}$.

Good exponential correlations between the two topological variables, $\rho$ and $\nabla^{2} \rho$, versus the interatomic distance are found for 1-3 and 1-4 type interactions, with $R^{2}$ larger than 0.97 . In contrast, for $1-2$ type interactions the $R^{2}$ values are only 0.89 and 0.83 for the $\rho$ and $\nabla^{2} \rho$, respectively. Two sets of points are observed for this kind of 1-2 interaction when the Laplacian is represented (Figure 5, panel $b$ ). One group of points is concentrated in a very small interval of distances (between 2.05 and $2.10 \AA$ ), and shows an unclear pattern with regard to the interacting atoms, which deviates from the expected behavior. The representation of the geometrical $\mathrm{O} \cdots \mathrm{H}-\mathrm{O}$ angle versus the interatomic $\mathrm{O} \cdots \mathrm{H}$ distance, shows that these points belong to 1-2 type interactions between the aldehyde moiety and the hydroxyl group (attached to C2) of the open-chain D-ribose with geometrical angles less than $117^{\circ}$.

The explicit water molecule plays a key role in the stabilization of sugars' conformation. In the most stable minima it forms an intermolecular bridge, acting both as HBA and $\mathrm{HBD}$. The electron density at the $\mathrm{BCP}$ of the intermolecular sugar- $\mathrm{H}_{2} \mathrm{O} \mathrm{HBs}$ ranges between 0.005 and $0.040 \mathrm{au}$, and its Laplacian, between 0.019 and 0.141 au, being its upper limit larger than in the intramolecular ones. The NBO $E^{(2)}$ energies are in an interval between 2.41 and $59.89 \mathrm{~kJ} \mathrm{~mol}^{-1}$.

3. Nonchiroptical Vibrational Study: IR and Raman Spectroscopies. Figures 6 and 7 show the IR and Raman spectra of D-ribose and 2-deoxy-D-ribose, recorded in $\mathrm{H}_{2} \mathrm{O}$ and $\mathrm{D}_{2} \mathrm{O}$ solutions and in the solid phase (powder sample), compared with the theoretical spectra of the most stable set of $\alpha$-pyranose and $\beta$-pyranose anomers, which are the most populated according to the quantum chemical calculations in PCM-water (M06-2X/6-311++G(d,p) and B3LYP/6-311++G$(\mathrm{d}, \mathrm{p}))$ and PCM plus an explicit water molecule (M06-2X/ $6-311++G(d, p))$, and expected to be mainly present in aqueous solutions. Figures S5 to S12 of the Supporting Information material provide an extensive comparison of the experimental and theoretical results for those readers interested in a more detailed analysis.

The theoretical spectra have been weighted according to the predicted populations of the most stable conformers (see Table 3). As shown in Figures 6 and 7 (panels $b$ and $d$ ) and discussed below, the experimental spectra seem to prove the presence of open-chain structures in the case of 2-deoxy-Dribose in solution. Thus, in spite of the fact that the PCM and $\mathrm{PCM}+\mathrm{H}_{2} \mathrm{O}$ M06-2X calculations do not predict the presence of those forms, the predicted B3LYP populations for openchain forms, that is, around $2.3 \%$ for D-ribose and $8.9 \%$ for 2-deoxy-D-ribose, were assumed in all the theoretical spectra shown in Figures 6, 7, 8, and 9.

In general, our theoretical spectra for both carbohydrates are in good agreement with the experimental ones. The PCM theoretical spectra agree well with experimental spectra, but there are some regions in which the theoretical results are improved when an explicit molecule of water is added to continuum solvent calculations. First, focusing our attention on the IR spectra of D-ribose, we can see that the $1600-1400 \mathrm{~cm}^{-1}$ region, where $\mathrm{C}-\mathrm{O}-\mathrm{H}$ and $\mathrm{H}_{2} \mathrm{O}$ bendings are present, and the $700-500 \mathrm{~cm}^{-1}$ one are in better agreement with the use of the $\mathrm{PCM}+\mathrm{H}_{2} \mathrm{O}$ M06-2X calculation. For 2-deoxy-D-ribose something similar occurs. The $1600-1400 \mathrm{~cm}^{-1}$ region is better predicted again and, in this case, also the $900-800 \mathrm{~cm}^{-1}$ one, which involves ring deformations. Second, the Raman spectra of these carbohydrates also show a region where the $\mathrm{PCM}+\mathrm{H}_{2} \mathrm{O}$ 


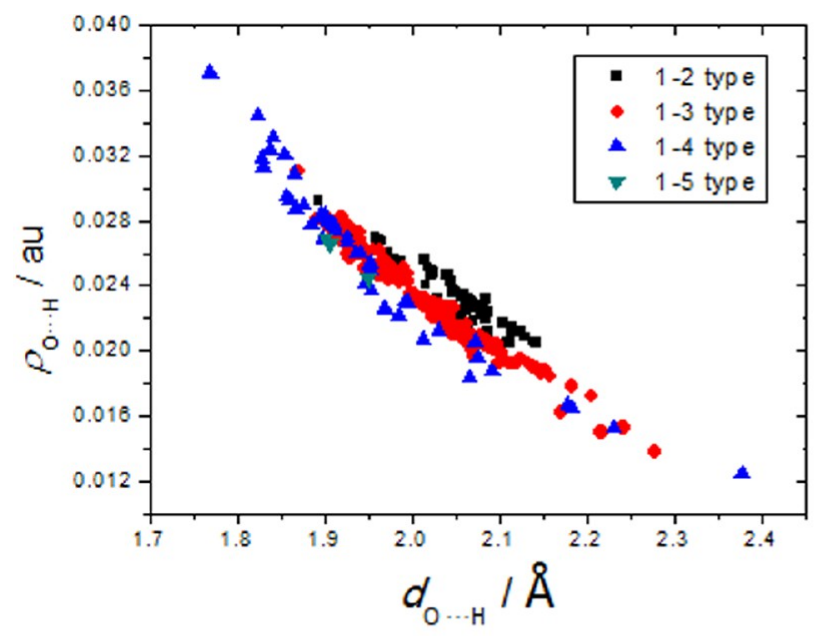

(a)

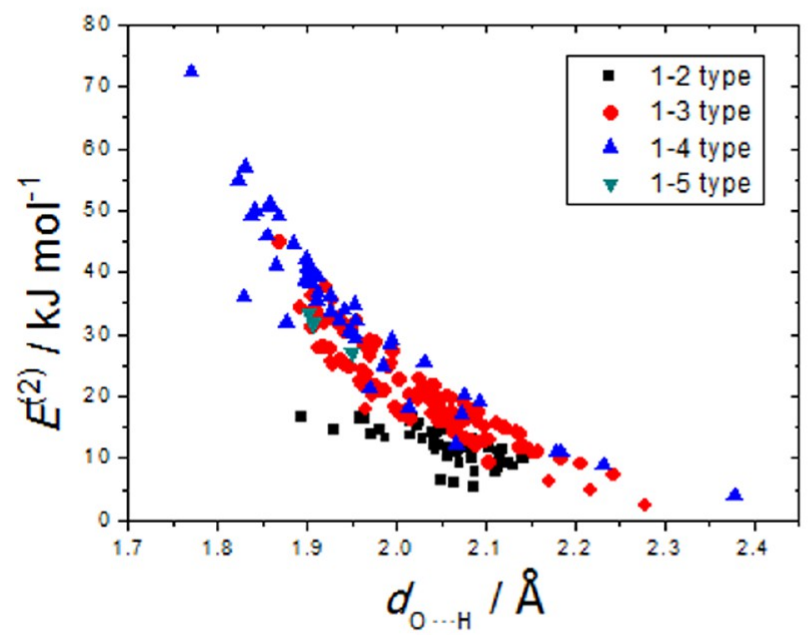

(c)

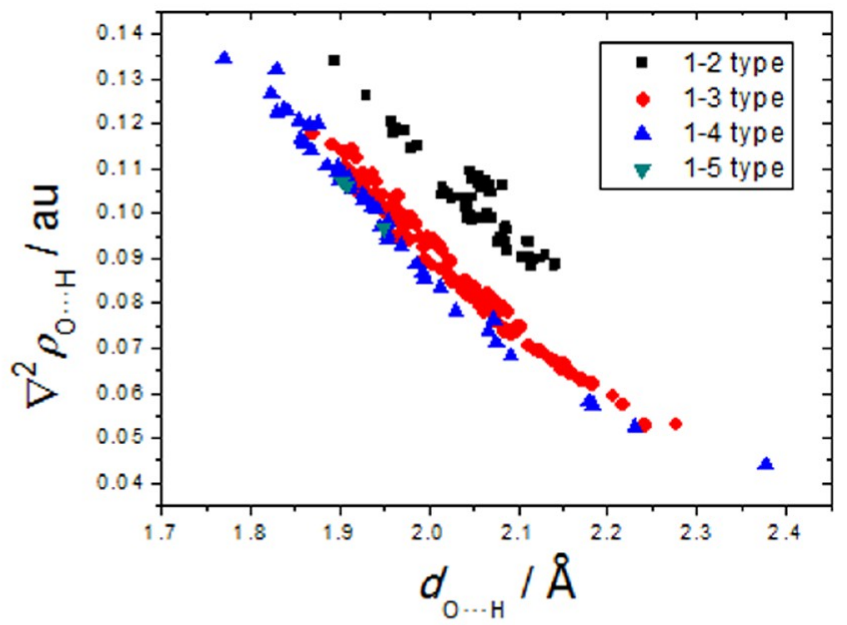

(b)

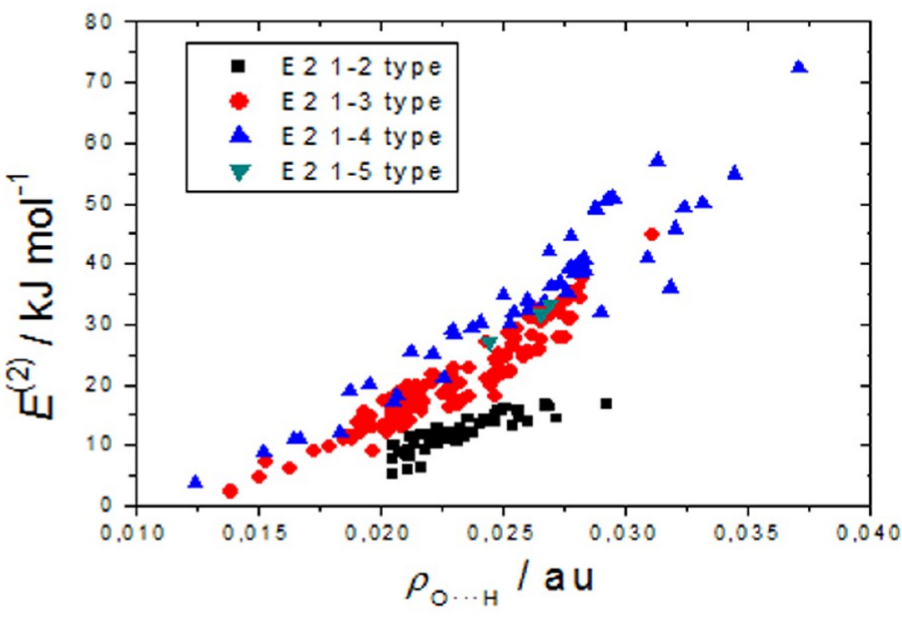

(d)

Figure 5. Representation of $(a)$ electron density $\rho_{\mathrm{O} \cdots \mathrm{H}}$ at the $\mathrm{BCP}$ in au; $(b)$ its Laplacian $\nabla^{2} \rho_{\mathrm{O} \cdots \mathrm{H}}$ in au; and (c) $E^{(2)} \mathrm{NBO}$ energy in kJ mol ${ }^{-1}$ versus the $\mathrm{O} \cdots \mathrm{H}$ interatomic distance in $\AA$. In $(d)$ is represented the $E^{(2)}$ NBO energy versus the electron density. Black squares refer to $1-2$ type interactions, red circles to $1-3$ ones, blue triangles to $1-4$ ones, and green inverse triangles to $1-5$ ones. All data extracted from all minima in 2-deoxy-D-ribose and D-ribose with relative energy less than $10 \mathrm{~kJ} \mathrm{~mol}^{-1}$.

model works better than the PCM alone one. For instance, the $1450-1200 \mathrm{~cm}^{-1}$ region, with contributions of $\mathrm{C}-\mathrm{O}-\mathrm{H}$ bending, $\mathrm{C}-\mathrm{H}$ wagging, and $\mathrm{CH}_{2}$ rocking. Besides, our Raman spectrum for D-ribose in aqueous solution agrees well with that obtained by Wen et al. in the $1600-600 \mathrm{~cm}^{-1}$ region. ${ }^{24}$

Our main spectral features can confirm the major presence of pyranoses, and even if the furanose forms were present in the aqueous solutions, most of the bands which could be assigned to furanose forms can also be assigned to the pyranose structures. In fact, many bands which appear in the theoretical spectra of the furanoses appear at the same wavenumbers in those of pyranoses. Thus, we cannot confirm the presence of furanoses, adding the fact that, theoretically, pyranoses are much more stable than furanose forms. Moreover, some theoretical intense bands proper of furanoses do not appear in the experimental spectra. Thus, in Raman spectrum of 2-deoxy-Dribose, our bands at $1263 \mathrm{~cm}^{-1}, 556 \mathrm{~cm}^{-1}$, and at $512 \mathrm{~cm}^{-1}$ are well predicted with the contribution of pyranose forms, but these bands are predicted to be very weak for the furanose forms. Mathlouthi et al. ${ }^{16}$ assigned the presence of furanose forms to Raman bands which appeared at $1186 \mathrm{~cm}^{-1}$ (very weak), $1082 \mathrm{~cm}^{-1}$ (strong), and at $512 \mathrm{~cm}^{-1}$ (medium). However, our theoretical spectra of pyranose forms reproduce these bands well, but they are reproduced more weakly for furanose forms. If we assign these bands to furanose forms, we would have to observe two bands of comparable intensity at $813 \mathrm{~cm}^{-1}$ and at $874 \mathrm{~cm}^{-1}$. Likewise, pyranoses reproduce them with different intensity, as we can also see experimentally. Moreover, the $1400-1200 \mathrm{~cm}^{-1}$ region is better reproduced by pyranose forms than by furanose forms. Besides, in IR spectra of this monosaccharide, the bands observed at 1010 $\mathrm{cm}^{-1}$ and at $977 \mathrm{~cm}^{-1}$ are better predicted by the pyranose model.

If we focus our attention on the Raman spectra of D-ribose, we can see that the intense bands at $1469 \mathrm{~cm}^{-1}, 1260 \mathrm{~cm}^{-1}$, $1121 \mathrm{~cm}^{-1}$, and at $1078 \mathrm{~cm}^{-1}$ are better structured by theoretical spectra of pyranoses, and they are predicted less intense by furanose ones. Mathlouthi et al. ${ }^{16}$ assigned the Raman bands at $1158 \mathrm{~cm}^{-1}$ (shoulder), $1078 \mathrm{~cm}^{-1}$ (strong), $916 \mathrm{~cm}^{-1}$ (weak), $830 \mathrm{~cm}^{-1}$ (very weak), $596 \mathrm{~cm}^{-1}$ (weak), and at $462 \mathrm{~cm}^{-1}$ (weak) to the presence of furanose forms. If we assign these bands to the presence of furanose forms, we would also observe a band at $1185 \mathrm{~cm}^{-1}$ in the experimental spectra and we do not see this feature. On the contrary, IR features of furanose and pyranose 

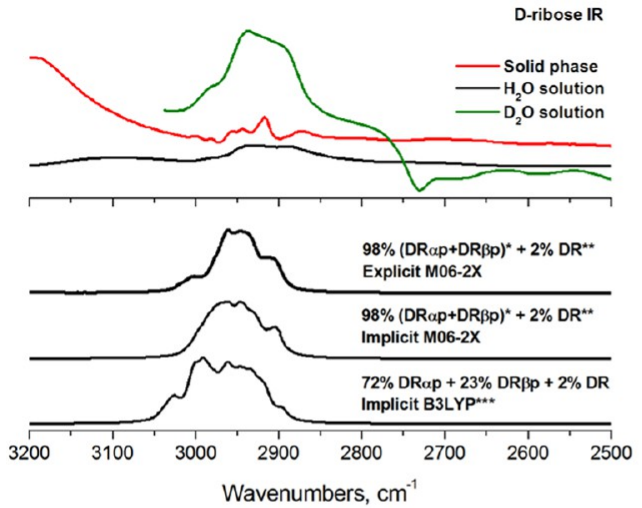

(a)
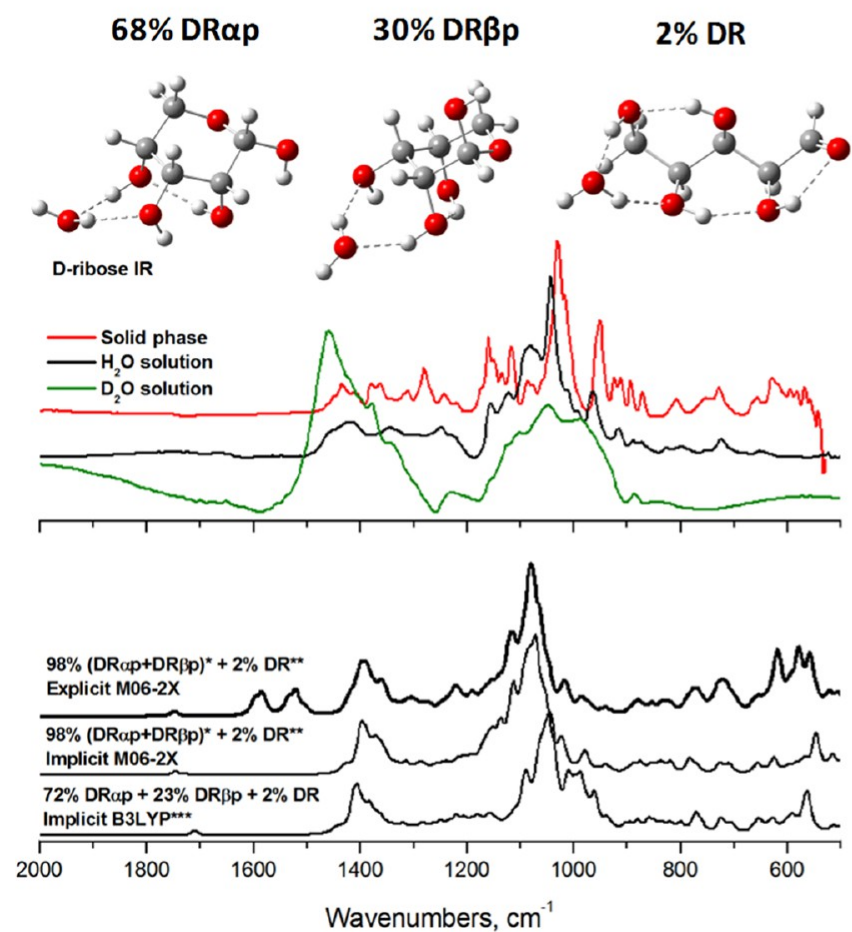

(c)

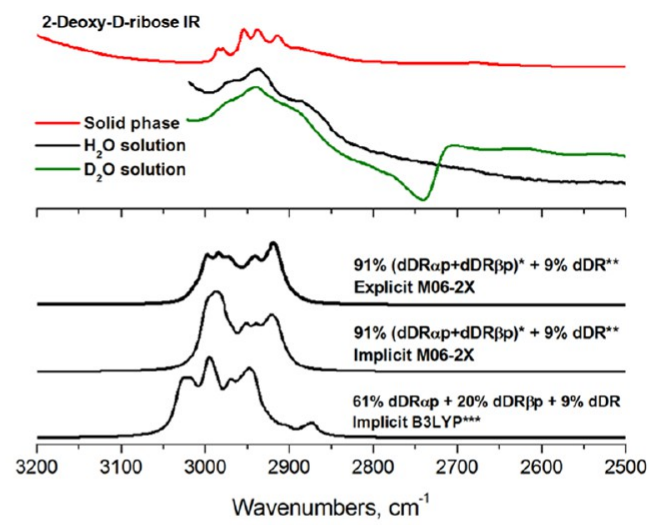

(b)
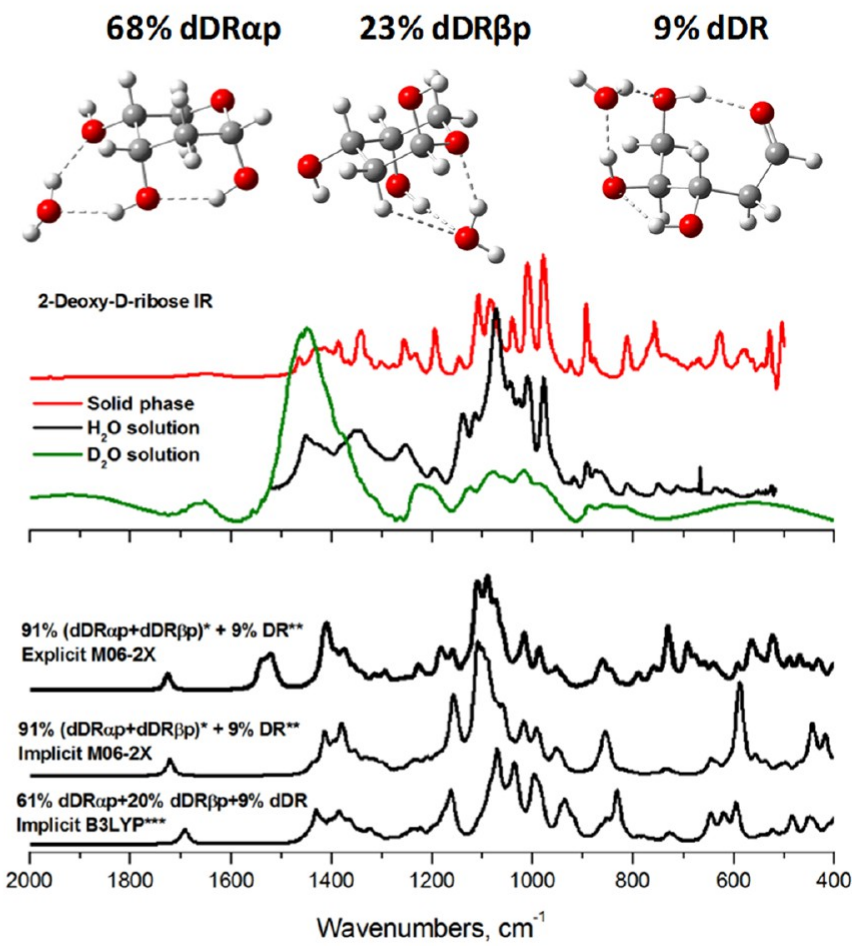

(d)

Figure 6. Experimental (top) and scaled predicted (bottom) IR spectra of D-ribose (panels $a$ and $c$ ) and 2-deoxy-D-ribose (panels $b$ and $d$ ) in the $3200-2500 \mathrm{~cm}^{-1}$ and $2000-400 \mathrm{~cm}^{-1}$ spectral regions. In the four panels, experimental IR spectra in solid phase (in red), $\mathrm{H}_{2} \mathrm{O}$ (in black), and $\mathrm{D}_{2} \mathrm{O}$ (in green) solutions are shown at the top. The solutions of $\mathrm{H}_{2} \mathrm{O}$ and $\mathrm{D}_{2} \mathrm{O}$ were prepared with a molarity of 4 . At the bottom, theoretical spectra are weighted with the population of the most stable conformers. NIST scaling frequency factor of 0.967 (B3LYP) and 0.95 (M06-2X), Lorentzian function, pitch $=1 \mathrm{~cm}^{-1}$, fwhm (Full Width Half Maximum) $=8 \mathrm{~cm}^{-1}$. *PCM/M06-2X populations of pyranose forms of D-ribose and 2-deoxy-Dribose are $71 \% \mathrm{DR} \alpha \mathrm{p}: 29 \% \mathrm{DR} \beta \mathrm{p}$ and $87 \% \mathrm{dDR} \alpha \mathrm{p}: 13 \% \mathrm{dDR} \beta \mathrm{p}$. $\left(\mathrm{PCM}+\mathrm{H}_{2} \mathrm{O}\right) / \mathrm{M} 06-2 \mathrm{X}$ populations of pyranose forms of D-ribose and 2-deoxy-Dribose are: $69 \% \mathrm{DR} \alpha \mathrm{p}: 31 \% \mathrm{DR} \beta \mathrm{p}$ and $75 \% \mathrm{dDR} \alpha \mathrm{p}: 25 \% \mathrm{dDR} \beta \mathrm{p}$. These populations are multiplied by 0.98 and 0.91 , respectively, in order to get $100 \%$ when open-chain forms are added. $* *$ Populations of open-chain forms coming from the B3LYP calculations. ***B3LYP populations do not sum $100 \%$ because of the percentages of $10 \%$ and $3 \%$ of furanose forms for 2-deoxy-D-ribose and for D-ribose, respectively.

forms are more similar for this carbohydrate and it is difficult to get a clear conclusion with only the assignment of the IR patterns.

With only the most stable set of pyranose conformers (up to $5 \mathrm{~kJ} \mathrm{~mol}^{-1}$ ) taken into account, the experimental spectra can be reproduced in a suitable way, especially whole Raman spectra and $1200-900 \mathrm{~cm}^{-1}$ region in IR ones. The populations of the open-chain forms are predicted to be about $2.3 \%$ for D-ribose and $8.9 \%$ for 2-deoxy-D-ribose (B3LYP), which contribute to the total theoretical vibrational spectra of these species with an additional band at $1650 \mathrm{~cm}^{-1}$, corresponding to the normal mode associated to $\mathrm{C}=\mathrm{O}$ stretching (or $\mathrm{C}=\mathrm{C}$ stretching for the enediol form), which is observed experimentally as a weak band in Raman and IR spectra of their aqueous solutions. But nothing can be confirmed in the IR case because water absorbs at this wavenumber. So, the IR and Raman spectra in $\mathrm{D}_{2} \mathrm{O}$ solutions were recorded in order to throw light on this point. However, the band was not observed in the spectra of D-ribose. On the contrary, and according to the quantum chemical calculations which predict a higher population of open-chain forms for 2-deoxy-D-ribose, the band appears in IR spectra of $\mathrm{D}_{2} \mathrm{O}$ solution of this last monosaccharide. The fact that this band appears in Raman spectrum of the aqueous solution in the 


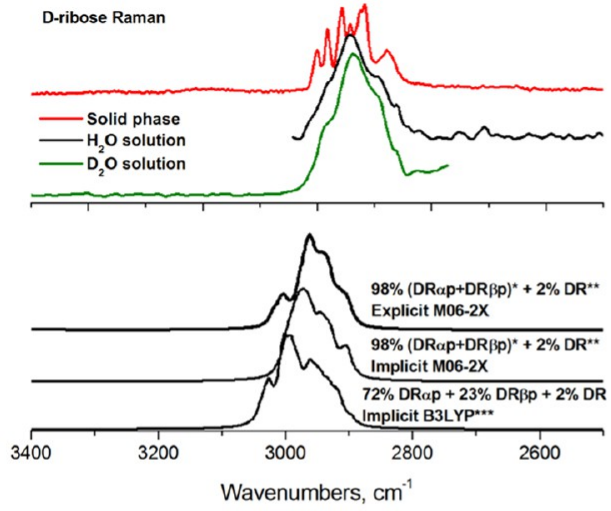

(a)
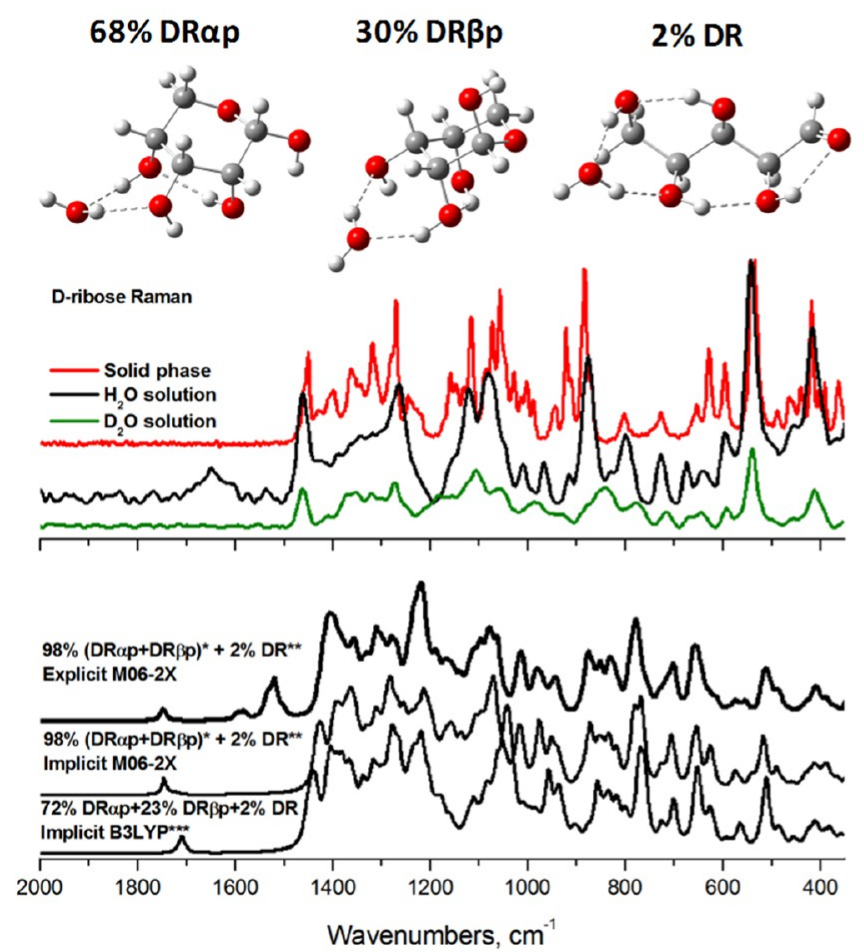

(c)

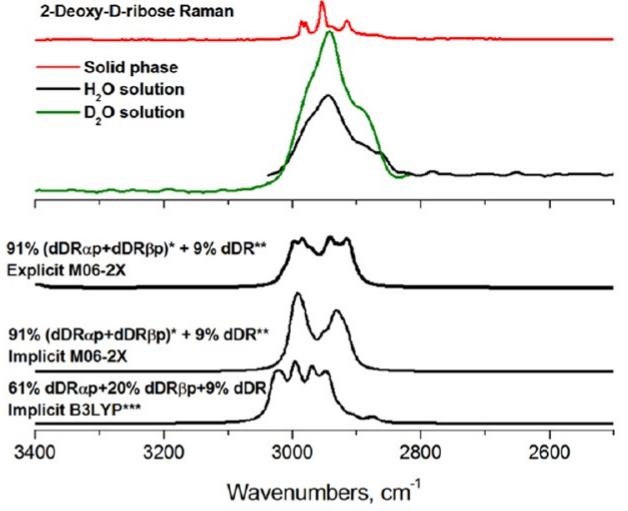

(b)
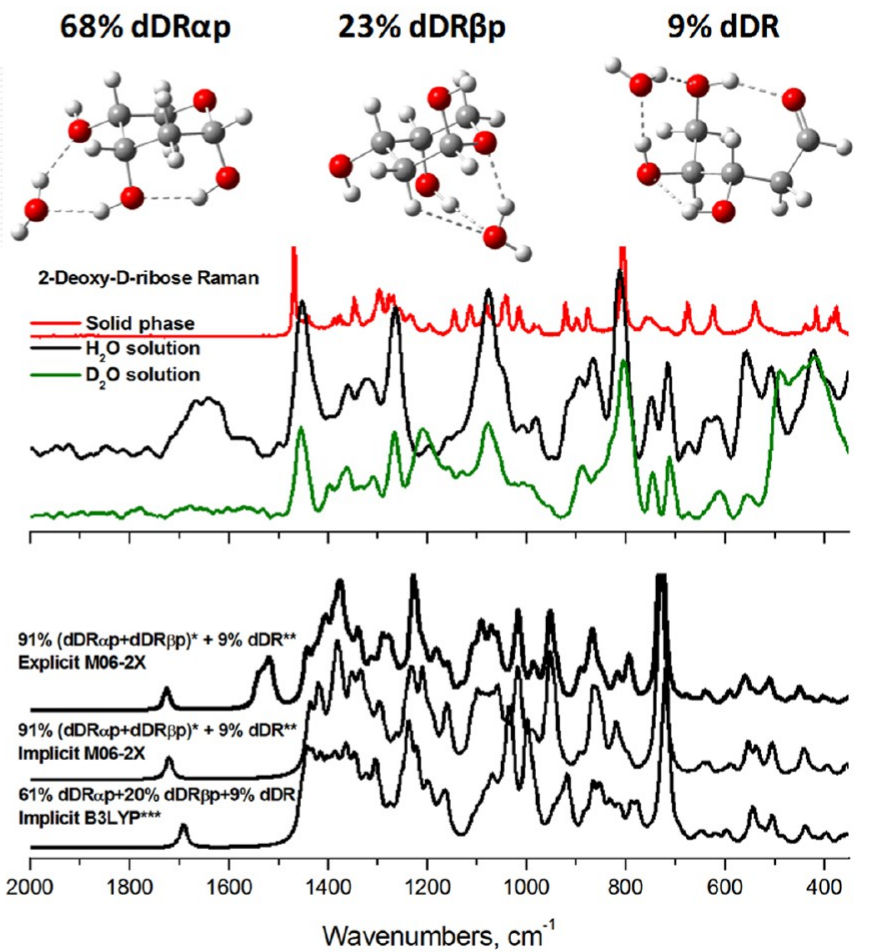

(d)

Figure 7. Experimental (top) and scaled predicted (bottom) Raman spectra of D-ribose (panels $a$ and $c$ ) and 2-deoxy-D-ribose (panels $b$ and $d$ ) in the $3400-2500 \mathrm{~cm}^{-1}$ and $2000-350 \mathrm{~cm}^{-1}$ spectral regions. In the four panels, experimental Raman spectra in solid phase (in red), $\mathrm{H}_{2} \mathrm{O}$ (in black) and $\mathrm{D}_{2} \mathrm{O}$ (in green) solutions are shown at the top. The solutions of $\mathrm{H}_{2} \mathrm{O}$ and $\mathrm{D}_{2} \mathrm{O}$ were prepared with a molarity of 4 . At the bottom, theoretical spectra are weighted with the population of the most stable conformers. NIST scaling frequency factor of 0.967 (B3LYP) and 0.95 (M06-2X), Lorentzian function, pitch $=1 \mathrm{~cm}^{-1}$, fwhm (Full Width Half Maximum) $=8 \mathrm{~cm}^{-1}$. $* \mathrm{PCM} / \mathrm{M06}$-2X populations of pyranose forms of D-ribose and 2-deoxy-Dribose are 71\% DR $\alpha \mathrm{p}: 29 \% \mathrm{DR} \beta \mathrm{p}$ and $87 \% \mathrm{dDR} \alpha \mathrm{p}: 13 \% \mathrm{dDR} \beta \mathrm{p} .\left(\mathrm{PCM}+\mathrm{H}_{2} \mathrm{O}\right) / \mathrm{M} 06-2 \mathrm{X}$ populations of pyranose forms of D-ribose and 2-deoxy-Dribose are: $69 \% \mathrm{DR} \alpha \mathrm{p}: 31 \% \mathrm{DR} \beta \mathrm{p}$ and $75 \% \mathrm{dDR} \alpha \mathrm{p}: 25 \% \mathrm{dDR} \beta \mathrm{p}$. These populations are multiplied by 0.98 and 0.91 , respectively, in order to get $100 \%$ when open-chain forms are added. **Populations of open-chain forms coming from the B3LYP calculations. ***B3LYP populations do not sum $100 \%$ because of the percentages of $10 \%$ and $3 \%$ of furanose forms for 2-deoxy-D-ribose and for D-ribose, respectively.

case of D-ribose and not in $\mathrm{D}_{2} \mathrm{O}$, and that it is observed more strongly in $\mathrm{H}_{2} \mathrm{O}$ solution than in $\mathrm{D}_{2} \mathrm{O}$ for 2-deoxy-D-ribose, is logical. The explanation is that the $\mathrm{D}-\mathrm{O} \cdots \mathrm{D}$ bond is less favored than $\mathrm{H}-\mathrm{O} \cdots \mathrm{H}$ one, consequently the formation of open-chain forms is a reaction less assisted in $\mathrm{D}_{2} \mathrm{O}$ solution, considering also that a hydrogen is necessary to start it. ${ }^{64,65}$ Nevertheless, in the solid Raman and IR spectra this band is not observed, and they are in fair agreement with theoretical ones only considering pyranose forms. Consequently, we can conclude that $\alpha$-pyranose and $\beta$-pyranose forms are present in the solid state, being a majority, as was reported by Šišak et al. ${ }^{18}$

Besides, Raman spectra in aqueous solution changing the temperature were recorded for the two carbohydrates (see Figure 8). There were no appreciable changes in spectral features. In fact, the band at $1650 \mathrm{~cm}^{-1}$ did not increase as a function of temperature. ${ }^{17}$ Perhaps an addition of acid catalyst could assist the creation of open-chain forms. ${ }^{66}$

4. Chiroptical Vibrational Response: VCD Spectroscopy.

Because of the chirality of D-ribose and 2-deoxy-D-ribose, it was 


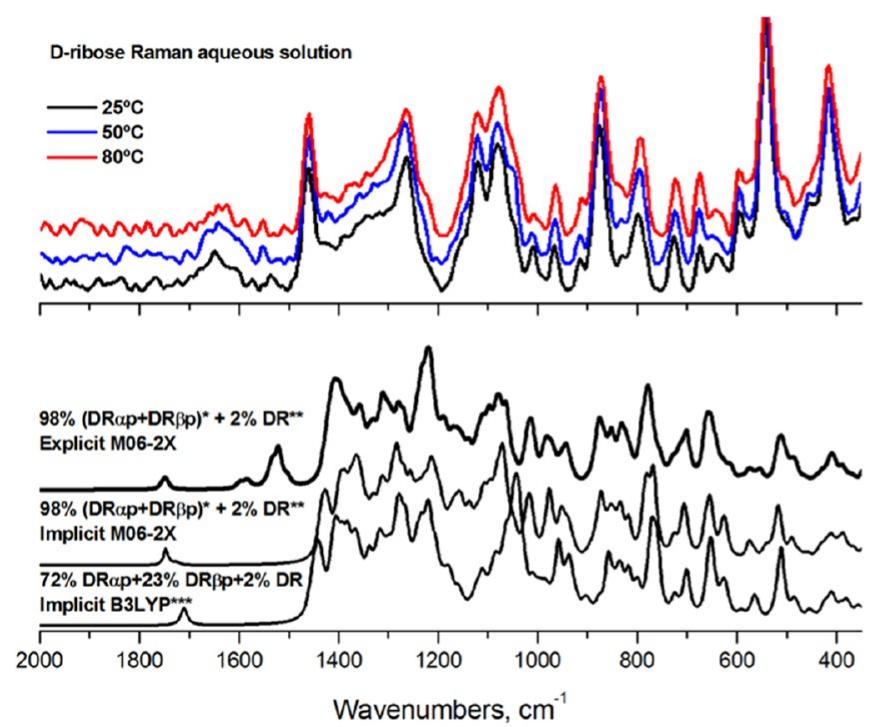

(a)
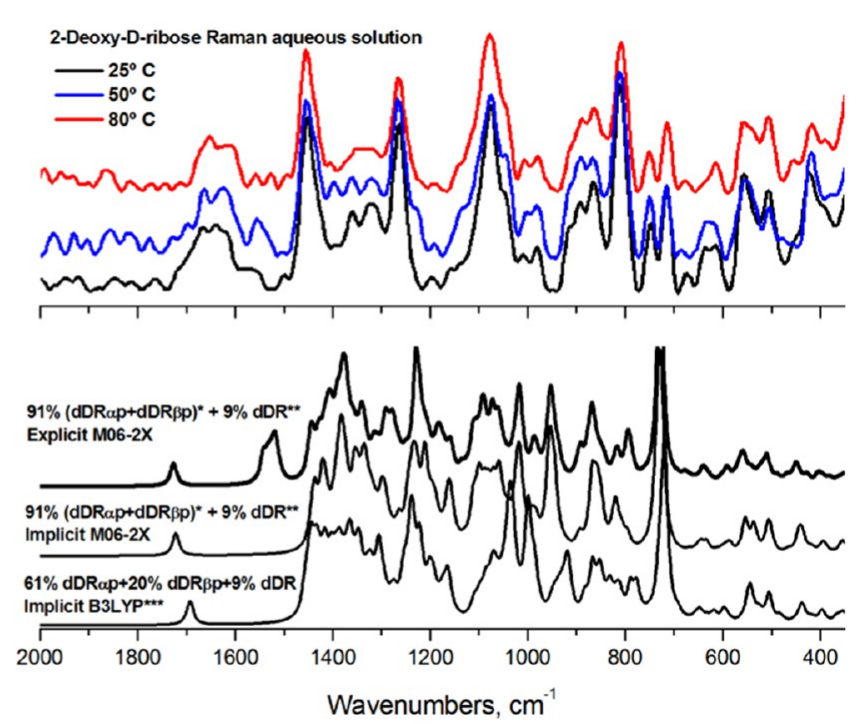

(b)

Figure 8. Experimental (top) and scaled predicted (bottom) Raman spectra of D-ribose (a) and 2-deoxy-D-ribose $(b)$ in the $2000-350 \mathrm{~cm}^{-1} \mathrm{spectral}$ region. In the two panels, experimental Raman spectra in aqueous solution with changes of temperature: $25{ }^{\circ} \mathrm{C}$ (in black), $50{ }^{\circ} \mathrm{C}$ (in blue), and $80^{\circ} \mathrm{C}$ (in red) at the top. The solutions were prepared with a molarity of 4 . At the bottom, theoretical spectra are weighted with the population of the most stable conformers of $\alpha$-pyranose, $\beta$-pyranose, and open-chain forms according to the PCM/B3LYP and the PCM and PCM $+\mathrm{H}_{2} \mathrm{O}$ M06-2X methods, being assumed B3LYP population for open-chain forms. NIST scaling frequency factor of 0.967 (B3LYP) and 0.95 (M06-2X), Lorentzian function, pitch $=1 \mathrm{~cm}^{-1}$, fwhm (Full Width Half Maximum) $=8 \mathrm{~cm}^{-1}$. *PCM/M06-2X populations of pyranose forms of D-ribose and 2-deoxy-Dribose are 71\% DR $\alpha \mathrm{p}: 29 \% \mathrm{DR} \beta \mathrm{p}$ and 87\% dDR $\alpha \mathrm{p}: 13 \% \mathrm{dDR} \beta \mathrm{p}$. $\left(\mathrm{PCM}+\mathrm{H}_{2} \mathrm{O}\right) / \mathrm{M} 06-2 \mathrm{X}$ populations of pyranose forms of D-ribose and 2-deoxy-Dribose are: $69 \% \mathrm{DR} \alpha \mathrm{p}: 31 \% \mathrm{DR} \beta \mathrm{p}$ and $75 \% \mathrm{dDR} \alpha \mathrm{p}: 25 \% \mathrm{dDR} \beta \mathrm{p}$. These populations are multiplied by 0.98 and 0.91 , respectively, in order to get $100 \%$ when open-chain forms are added. **Populations of open-chain forms coming from the B3LYP calculations. ***B3LYP populations do not sum $100 \%$ because of the percentages of $10 \%$ and $3 \%$ of furanose forms for 2 -deoxy-D-ribose and for D-ribose, respectively.

expected that some interesting structural information of both monosaccharides could be obtained from a detailed study of their Vibrational Circular Dichroism (VCD) spectra. For this reason, we recorded the VCD spectra of solid (mulls and thin films) and solution $\left(\mathrm{H}_{2} \mathrm{O}\right.$ and $\left.\mathrm{D}_{2} \mathrm{O}\right)$ samples of both carbohydrates, and then, they were analyzed by comparison with those calculated from the $\left(\mathrm{PCM}+\mathrm{H}_{2} \mathrm{O}\right) / \mathrm{M} 06-2 \mathrm{X}$ and the PCM M062X-B3LYP methods. If we compare our results with those obtained by Tummalapalli et al., ${ }^{20}$ we can find two couplets which appear in both works, i.e., one $(-,+)$ couplet with components at $1265 \mathrm{~cm}^{-1}$ and at $1240 \mathrm{~cm}^{-1}$ of D-ribose$(\mathrm{OD})_{4}$ and the $(-,+)$ other one at $1159 \mathrm{~cm}^{-1}$ and at $1125 \mathrm{~cm}^{-1}$ in D-ribose- $(\mathrm{OH})_{4}$, both in DMSO- $d_{6}$ solution. Tummalapalli et al. reproduce neither the first one in the D-ribose- $(\mathrm{OH})_{4}$ spectrum nor the second one in the D-ribose-(OD) $)_{4}$ one. On the contrary, we observe the two couplets in all our spectra. In addition, they do not include the exocyclic $\mathrm{C}-\mathrm{O}$ stretching motions of the D-ribose for their correlation between the structural details and the VCD spectra of deuterated D-sugars, because of the different signs of the two bands at $1159 \mathrm{~cm}^{-1}$ and at $1125 \mathrm{~cm}^{-1}$. They concluded that the VCD feature at $1150 \mathrm{~cm}^{-1}$ indicates that the overall orientation of hydroxyl groups can be deduced from the VCD studies. Concerning the $\mathrm{C}-\mathrm{O}-\mathrm{H}$ and $\mathrm{C}-\mathrm{C}-\mathrm{H}$ bending motions, they do not obtain measurable VCD features for D-ribose (detailed explanation is provided in the ref 20).

Later, Bose et al. $^{21}$ complemented these last results for D-ribose with the analysis of the VCD spectrum of this carbohydrate in DMSO- $d_{6}$ solution with the use of improved VCD instrumentation. The VCD pattern that these authors observed in their spectrum and that we also observed in our spectra of D-ribose in $\mathrm{H}_{2} \mathrm{O}$ and $\mathrm{D}_{2} \mathrm{O}$ solutions is the $(+,-,+)$ structure at $1347 \mathrm{~cm}^{-1}$, at $1263 \mathrm{~cm}^{-1}$, and at $1225 \mathrm{~cm}^{-1}$ (broad band). They also observed a $(-,+)$ couplet with components at $1460 \mathrm{~cm}^{-1}$ and at $1435 \mathrm{~cm}^{-1}$, which was weaker in our spectra, but the (-,-,-) bands observed by authors of ref 21 at $1337 \mathrm{~cm}^{-1}$, at $1311 \mathrm{~cm}^{-1}$, and at $1287 \mathrm{~cm}^{-1}$ appeared in our spectra with different sign $(+,+,+)$. It could be due to the signal/noise ratio, because we measured the spectra in solution with 14000-28000 scans by blocks of 2000 scans, that is around $10 \mathrm{~h}$, and Bose et al. used $1 \mathrm{~h}$ of measurement for those spectra.

At this point, we can focus the discussion on our results. In the same way as for the analysis of the IR and Raman spectra, the PCM $+\mathrm{H}_{2} \mathrm{O}$ model improves some VCD features of both carbohydrates. Thus, for the VCD spectrum of D-ribose in water solution, the $(+,+,-,-)$ bands at $1125,1089,1056$, and $1037 \mathrm{~cm}^{-1}$ are better predicted. In the case of 2-deoxy-D-ribose, it occurs for the $(-,+)$ couplet at 1116 and $1077 \mathrm{~cm}^{-1}$. The analysis of the VCD bands, intensities and signs, observed and calculated for D-ribose and 2-deoxy-D-ribose, has been very helpful to conclude the presence of their $\alpha$ - and $\beta$-pyranose forms in both the solid and solution phases. The next paragraphs stand out the main VCD results obtained in this work in the $\mathrm{CH}$ stretching and 2000-900 $\mathrm{cm}^{-1}$ spectral regions.

In relation to $\mathrm{CH}$ stretching region, the two VCD spectra in $\mathrm{D}_{2} \mathrm{O}$ solution (see Figure 9 panels $a$ and $b$ ) display a sequence of positive $\mathrm{CH}$ stretching bands, which is consistent with the signs observed in the spectra of the B3LYP and M06-2X calculations. Thus (i) for D-ribose, the $(+,+,+)$ pattern at 3016, 2993, and $2970 \mathrm{~cm}^{-1}$ can be observed in $\mathrm{D}_{2} \mathrm{O}$ solution and is well predicted by theoretical spectra. (ii) Concerning 2-deoxyD-ribose, we can remark about the agreement of some relevant bands again. In $\mathrm{D}_{2} \mathrm{O}$ solution, the $(+,+,+,+)$ bands at 2988 , 


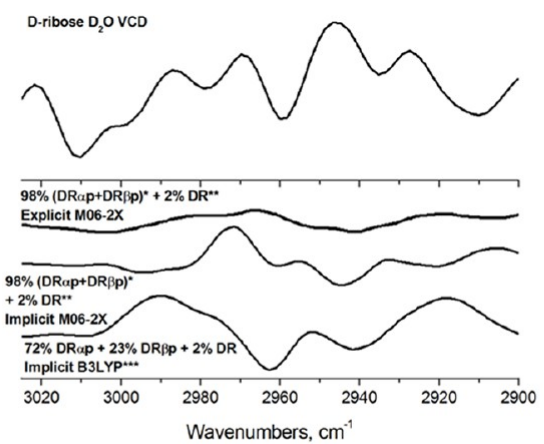

(a)

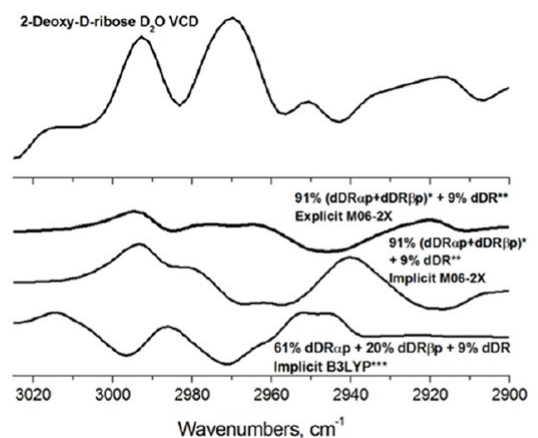

(b)
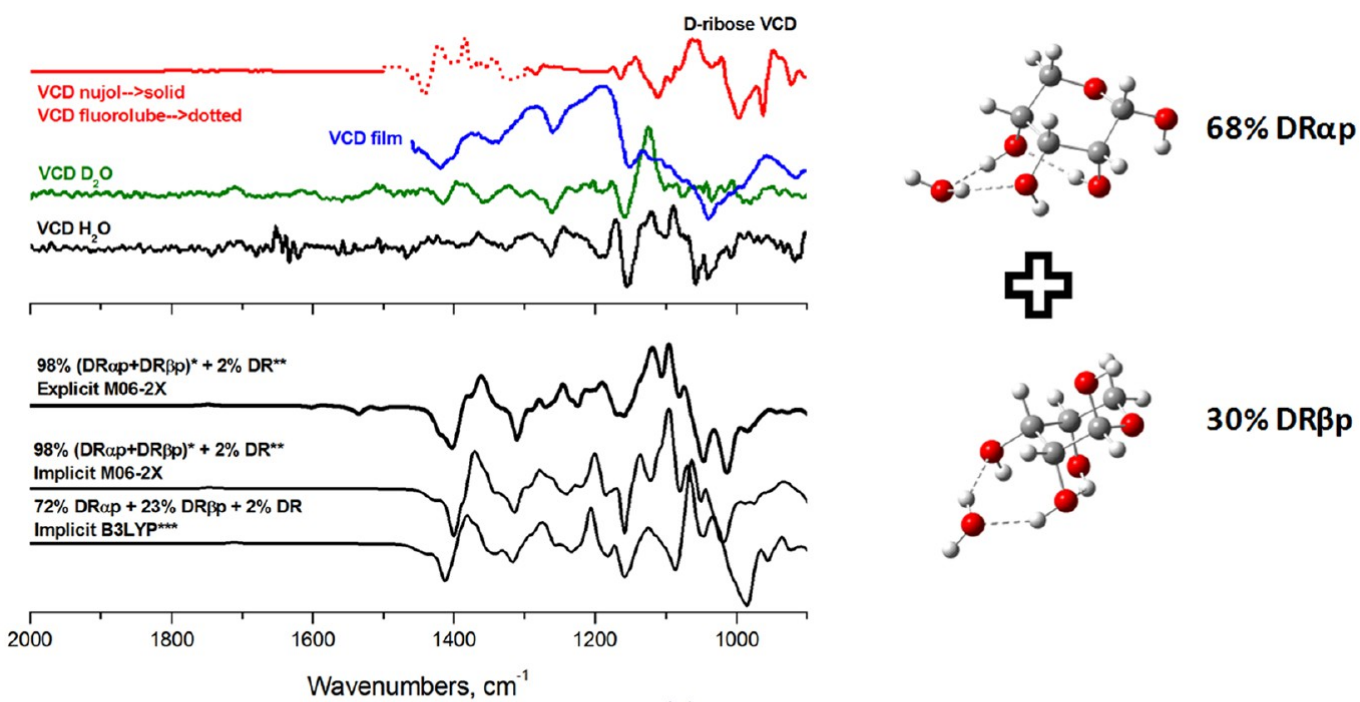

$30 \%$ DR $\beta p$

(c)
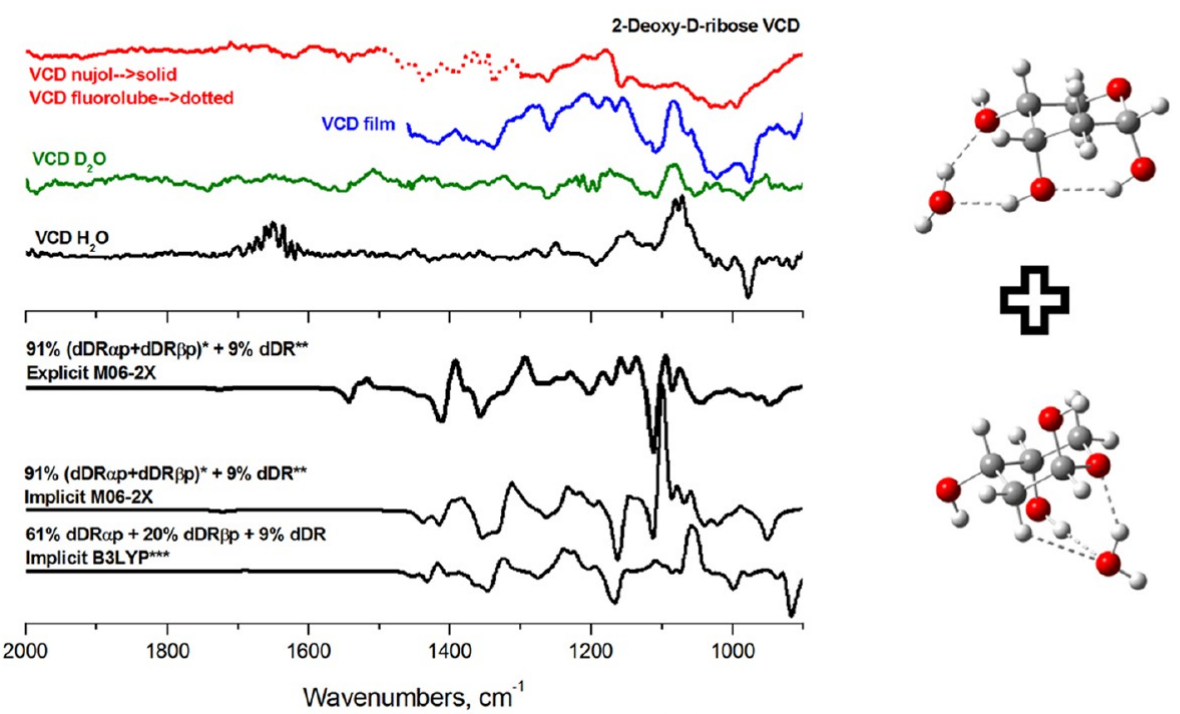

$68 \%$ dDR $\alpha p$

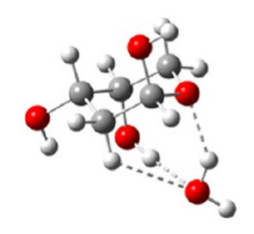

$23 \%$ dDR $\beta p$

(d)

Figure 9. Experimental (top) and scaled predicted (bottom) VCD spectra of D-ribose (panels $a$ and $c$ ) and 2-deoxy-D-ribose (panels $b$ and $d$ ) in the $3025-2900 \mathrm{~cm}^{-1}$ and $2000-900 \mathrm{~cm}^{-1}$ spectral regions. Top: Experimental VCD spectra in $\mathrm{D}_{2} \mathrm{O}$ solutions $(a$ and $b)$ and experimental VCD spectra in fluorolube (dotted line in red) and nujol mulls (solid line in red), film (in blue), $\mathrm{D}_{2} \mathrm{O}$ (in green), and $\mathrm{H}_{2} \mathrm{O}$ (in black) solutions ( $c$ and $d$ ). The solutions of $\mathrm{H}_{2} \mathrm{O}$ and $\mathrm{D}_{2} \mathrm{O}$ were prepared with a molarity of 4 . Bottom: Theoretical spectra are weighted with the population of the most stable conformers of $\alpha$-pyranose, $\beta$-pyranose, and open-chain forms according to the PCM/B3LYP and the PCM and PCM $+\mathrm{H}_{2} \mathrm{O}$ M06-2X methods, being assumed B3LYP population for open-chain forms. NIST scaling frequency factor of 0.967 (B3LYP) and 0.95 (M06-2X), Lorentzian function, pitch $=1 \mathrm{~cm}^{-1}$, fwhm (Full Width Half Maximum) $=8 \mathrm{~cm}^{-1}$. *PCM/M06-2X populations of pyranose forms of D-ribose and 2-deoxy-D-ribose are 71\% DR $\alpha$ p:29\% DR $\beta$ p and 87\% dDR $\alpha$ p:13\% dDR $\beta$ p. $\left(\mathrm{PCM}+\mathrm{H}_{2} \mathrm{O}\right) /$ M06-2X populations of pyranose forms of D-ribose and 2-deoxy-D-ribose are: 69\% DR $\alpha$ p:31\% DR $\beta$ p and 75\% dDR $\alpha$ p:25\% dDR $\beta$ p. These populations are multiplied by 0.98 and 0.91 , respectively, in order to get $100 \%$ when open-chain forms are added. **Populations of open-chain forms coming from the B3LYP calculations. ***B3LYP populations do not sum 100\% because of the percentages of $10 \%$ and $3 \%$ of furanose forms for 2-deoxy-D-ribose and for D-ribose, respectively. 
2969,2946 , and $2927 \mathrm{~cm}^{-1}$ are well predicted by the theoretical spectra.

Figure 9 (panels $c$ and $d$ ) shows VCD spectra of D-ribose and 2-deoxy-D-ribose in different conditions, i.e., $\mathrm{H}_{2} \mathrm{O}$ and $\mathrm{D}_{2} \mathrm{O}$ solutions and in the solid phase (thin film and fluorolube/nujol mulls) in the $2000-900 \mathrm{~cm}^{-1}$ spectral region, compared with the theoretical spectra previously stated. As in the preceding cases, they are in good agreement. The presence of pyranose forms is enough in order to reproduce the experimental VCD spectra. We can support this fact by the sign and position of several VCD features in the $\mathrm{C}-\mathrm{H}$ wagging, $\mathrm{C}-\mathrm{O}-\mathrm{H}$ bending and $\mathrm{C}-\mathrm{O}$ stretching regions, that is, for instance: (i) For D-ribose, the $(-,+)$ couplet at 1441 and $1421 \mathrm{~cm}^{-1}$ can be observed in the fluorolube mull spectrum and is well predicted by theoretical spectra. In addition, in film and solutions spectra another interesting $(+,-)$ couplet is observed at 1170 and $1154 \mathrm{~cm}^{-1}$ and a sequence of $(+,+,-,-)$ bands at 1125,1089 , 1056, and $1037 \mathrm{~cm}^{-1}$ are both also in good agreement with theoretical data. (ii) Concerning 2-deoxy-D-ribose, we can remark, likewise, the agreement of some relevant bands again. Thus, in its fluorolube mull spectrum, the $(+,+,+,-,+)$ bands sequence at $1378,1365,1346,1340$, and $1313 \mathrm{~cm}^{-1}$ and, in its film and solutions spectra, the $(-,+,-,+,-)$ bands set at 1191, $1153,1116,1077$, and $977 \mathrm{~cm}^{-1}$ newly match the experimental and theoretical results well.

All the observed VCD features in both solutions $\left(\mathrm{H}_{2} \mathrm{O}\right.$ and $\mathrm{D}_{2} \mathrm{O}$ ) and solid phase (thin films and mulls) are in good agreement, i.e., the main VCD features (intensities and signs) are conserved and only small frequency shifts are observed because of the different phases.

In summary, through the analysis of the chiroptical properties of D-ribose and 2-deoxy-D-ribose in relation with their structures, we can confirm the major presence of $\alpha$ - and $\beta$-pyranose forms in both solution and solid phases, with the first ones in major proportion in both monosaccharides, with an $\alpha / \beta$ ratio of $3: 1$, approximately, according to the theoretical calculations. In addition, IR and Raman spectroscopies seem to indicate the existence of a small amount of open-chain forms in the case of 2-deoxy-D-ribose in $\mathrm{D}_{2} \mathrm{O}$ and $\mathrm{H}_{2} \mathrm{O}$ solutions. Furanose forms could be present but it was not possible to observe any spectral feature which could be unambiguously assigned to the presence of furanose structures. For further comparison see Supporting Information. Our conclusions in terms of pyranose forms are in good agreement with those obtained in the literature. ${ }^{15-18,20,21,24,67}$ On the contrary, those references conclude the presence of a non-negligible amount of furanose forms, in different percentages, and our results are not able to reproduce this finding because all the spectral patterns which could be associated to furanose forms are also well reproduced with the presence of pyranose ones.

\section{CONCLUSIONS}

(1) The most stable set of conformers of each form of D-ribose and 2-deoxy-D-ribose was determined thanks to an exhaustive analysis of the quantum chemical energies. Five possible configurations for both carbohydrates were studied: open-chain, $\alpha$-pyranose, $\beta$-pyranose, $\alpha$-furanose, and $\beta$-furanose forms. A large number of conformational minima were obtained, especially for the open-chain configurations. The pyranose and furanose conformations have been characterized using the CremerPople puckering parameters $(P, \theta, \phi)$. In the two molecules studied, the $\alpha$-pyranose conformers are the most populated, followed by the $\beta$-pyranose ones. Only B3LYP results indicate the presence of significant populations of openchain and furanose forms, in contrast with the results obtained using the M06-2X hybrid functional.

(2) According to our results for these types of molecules, the M06-2X functional is recommended, instead of the B3LYP one, in order to obtain better results with regard to the estimation of their relative populations and the interpretation of their IR, VCD, and Raman spectra. Thus, some conclusions can be reached: (i) MP2 and M06-2X approaches give similar results in terms of relative energy; (ii) even in those cases that the B3LYP functional provides similar structures to the MP2 and M06-2X levels, the calculated relative energies are, in general, very different; (iii) in general, the spectroscopic experimental data agree better with the M06-2X and MP2 results than with B3LYP ones; (iv) the predicted B3LYP populations for the open-chain forms reproduce better, however, the experimental data than those performed at the M06-2X and MP2 methods.

(3) Intramolecular hydrogen bonds (HB) are the most important weak interactions taking place in 2-deoxy-Dribose and D-ribose. Four kinds of them are found attending to the number of atoms of the carbon skeleton, which separate the interacting groups: $1-2,1-3,1-4$, and 1-5. Geometrical, topological, and orbital parameters show narrower ranges of values in 1-2 type than in the rest of the cases. Correlation has been obtained when the electron density, its Laplacian, and the $E^{(2)} \mathrm{NBO}$ energy are represented versus the interatomic distance. Also, a correlation was observed between $E^{(2)}$ and the electron density.

(4) The experimental and theoretical spectra agree well for both carbohydrates. The implicit model reproduces well the experimental spectra, but there are some spectral regions in which the agreement is improved when an explicit molecule of water is added to continuum solvent calculations.

(5) The IR and Raman spectra in solution and in solid phase show evidence of the major presence of $\alpha$ - and $\beta$-pyranose forms, with the first ones in major proportion as much for D-ribose as for 2-deoxy-D-ribose, with an $\alpha / \beta$ ratio of 3:1, approximately, according to the theoretical calculations. Besides, these spectroscopies throw light on the presence of open-chain forms in solution in the case of 2-deoxy-D-ribose, because of the presence of a weak band at $1650 \mathrm{~cm}^{-1}$.

(6) Through the analysis of the chiroptical properties of D-ribose and 2-deoxy-D-ribose, in relation to their structures, by means of Vibrational Circular Dichroism (VCD), the major presence of pyranose forms was confirmed not only in solution but also in solid phase. However, the existence of open-chain forms was not rechecked because of too weak VCD signals.

(7) Furanose forms could be present, but it was not possible to observe any spectral feature which could be unambiguously assigned to the presence of furanose structures. In fact, all the spectral patterns which could be associated to furanose forms are also well reproduced with the presence of pyranose ones.

(8) The results obtained in this work could be useful for the study of building blocks which contain D-ribose or 2-deoxy-D-ribose. In addition, we have proven the utility 
of the methodology employed here in order to explore the conformational landscapes of the two monosaccharides studied. In this way, we think it could likewise be applied to analyze other carbohydrates in biological-like conditions.

\section{ASSOCIATED CONTENT}

\section{S Supporting Information}

SI1: Detailed tables of energies $\left(\mathrm{kJ} \mathrm{mol}^{-1}\right)$ and populations; SI2: The most stable conformers of the furanose ( $\alpha$ - and $\beta$-) forms of 2-deoxy-D-ribose and D-ribose in PCM and PCM plus an explicit water molecule calculated at the M06-2X/6-311+ $+\mathrm{G}(\mathrm{d}, \mathrm{p})$ computational level; SI3: The most stable conformers of the five forms of 2-deoxy-D-ribose and D-ribose in PCMwater calculated at the M06-2X/6-311++G(d,p) computational level; and SI4: Comparisons between IR, Raman, and VCD experimental spectra and PCM theoretical spectra, showing the theoretical contribution of each form for the most stable conformers ( $\alpha$-pyranose, $\beta$-pyranose, $\alpha$-furanose, $\beta$-furanose, and open-chain) of the two monosaccharides.This material is available free of charge via the Internet at http://pubs.acs.org.

\section{AUTHOR INFORMATION}

\section{Corresponding Authors}

*E-mail: ibon@iqm.csic.es.

*E-mail: jjlopez@ujaen.es.

\section{Notes}

The authors declare no competing financial interest.

\section{ACKNOWLEDGMENTS}

M.M.Q.M. thanks the University of Jaén for a predoctoral fellowship. L.M.A. thanks MICINN for a PhD grant (No. BES2010-031225). This work has been supported by the Junta de Andalucía (project P08-FQM-04096), MINECO (Project No. CTQ2012-35513-C02-02) and the Comunidad Autónoma de Madrid (Project MADRISOLAR2, ref S2009/PPQ-1533). Gratitude is also due to University of Jaén for continuing financial support and its CICT for instrumental facilities and to the CESGA and CTI (C.S.I.C.) for an allocation of computer time.

\section{REFERENCES}

(1) Azofra, L. M.; Alkorta, I.; Elguero, J.; Popelier, P. L. A. Conformational Study of the Open-Chain and Furanose Structures of D-erythrose and D-threose. Carbohydr. Res. 2012, 358, 96-105.

(2) Aviles-Moreno, J.-R; Huet, T. R. Sugars in the Gas Phase: The Conformational Properties of Erythrose, Threose, And Erythrulose Characterized by Quantum Chemistry Calculations. J. Mol. Struct.: THEOCHEM 2008, 858, 113-119.

(3) Cocinero, E. J.; Lesarri, A.; Écija, P.; Basterretxea, F. J.; Grabow, J.-U.; Fernández, J. A.; Castaño, F. Ribose Found in the Gas Phase. Angew. Chem. Int. Ed. 2012, 124, 3173-3178.

(4) Stern, J. H.; Hubler, P. M. Hydrogen Bonding in Aqueous Solutions of D-Ribose and 2-Deoxy-D-ribose. J. Phys. Chem. 1984, 88, $1680-1681$.

(5) Saenger, W. A Multi-Faceted Approach to Elucidate the Crystal Structure of D-Ribose: Similarities to Protein Structure Determination. Angew. Chem. Int. Ed. 2010, 49, 6487-6489.

(6) Suzuki, T.; Kawashima, H.; Kotoku, H.; Sota, T. Structural Fluctuation and Dynamics of Ribose Puckering in Aqueous Solution from First Principles. J. Phys. Chem. B 2005, 109, 12997-13005.

(7) Suzuki, T.; Sota, T. Circular Hydrogen Bond Networks on the Surface of $\beta$-Ribofuranose in Aqueous Solution. J. Phys. Chem. B 2005, 109, 12603-12611.
(8) Van Eijck, B. P.; Kroon, J. Molecular-Dynamics Simulations of $\beta$ d-Ribose and $\beta$-d-Deoxyribose solutions. J. Mol. Struct. 1989, 195, $133-146$

(9) Alkorta, I.; Popelier, P. L. A. Computational Study of Mutarotation in Erythrose and Threose. Carbohydr. Res. 2011, 346, 2933-2939.

(10) Qian, X.; Wei, X. Glucose Isomerization to Fructose from $\mathrm{Ab}$ Initio Molecular Dynamics Simulations. J. Phys. Chem. B 2012, 116, 10898-10904.

(11) Molteni, C.; Parrinello, M. Glucose in Aqueous Solution by First Principles Molecular Dynamics. J. Am. Chem. Soc. 1998, 120, 21682171.

(12) Azofra, L. M.; Alkorta, I.; Elguero, J. Theoretical Study of the Mutarotation of Erythrose and Threose: Acid Catalysis. Carbohydr. Res. 2013, 372, 1-8.

(13) Dejaegere, A. P.; Case, D. A. Density Functional Study of Ribose and Deoxyribose Chemical Shifts. J. Phys. Chem. A 1998, 102, 5280-5289.

(14) Jalbout, A. F.; Adamowicz, L.; Ziurys, L. M. Conformational Topology of Ribose: A Computational Study. Chem. Phys. 2006, 328, $1-7$.

(15) Angyal, S. J. The Composition of Reducing Sugars in Solution: Current Aspects. Adv. Carbohydr. Chem. Biochem. 1991, 49, 19-36.

(16) Mathlouthi, M.; Seuvre, A. M.; Koenig, J. L. F.T.-I.R. and LaserRaman Spectra of d-Ribose and 2-Deoxy-d-erythro-pentose ("2-deoxyd-ribose"). Carbohydr. Res. 1983, 122, 31-47.

(17) Yaylayan, V. A.; Ismail, A. A. Investigation of the Enolization and Carbonyl Group Migration in Reducing Sugars by FTIR Spectroscopy. Carbohydr. Res. 1995, 276, 253-265.

(18) Šišak, D.; McCusker, L. B.; Zandomeneghi, G.; Meier, B. H.; Bläser, D.; Boese, R.; Bernd Schweizer, W.; Gilmour, R.; Dunitz, J. D. The Crystal Structure of D-ribose - At Last! Angew. Chem. Int. Ed. 2010, 49, 4503-4505.

(19) Lemieux, R. U.; Anderson, L.; Conner, A. H. The Mutarotation of 2-Deoxy- $\beta$-d-erythro-pentose ("2-deoxy- $\beta$-d-ribose"). Conformations, Kinetics, and Equilibria. Carbohydr. Res. 1971, 20, 59-72.

(20) Tummalapalli, C. M.; Back, D. M.; Polavarapu, P. L. FourierTransform Infrared Vibrational Circular Dichroism of Simple Carbohydrates. J. Chem. Soc., Faraday Trans. 1988, 84, 2585-2594.

(21) Bose, P. K.; Polavarapu, P. L. Vibrational Circular Dichroism of Monosaccharides. Carbohydr. Res. 1999, 319, 172-183.

(22) Petrovic, A. G.; Bose, P. K.; Polavarapu, P. L. Vibrational Circular Dichroism of Carbohydrate Films Formed from Aqueous Solutions. Carbohydr. Res. 2004, 339, 2713-2720.

(23) Taniguchi, T.; Monde, K. Vibrational Circular Dichroism (VCD) Studies on Disaccharides in the $\mathrm{CH}$ Region: Toward Discrimination of the Glycosidic Linkage Position. Org. Biomol. Chem. 2007, 5, 1104-1110.

(24) Wen, Z. Q.; Barron, L. D.; Hecht, L. Vibrational Raman Optical Activity of Monosaccharides. J. Am. Chem. Soc. 1993, 115, 285-292.

(25) Becke, A. D. Density-Functional Thermochemistry 0.3. The Role of Exact Exchange. J. Chem. Phys. 1993, 98, 5648-5652.

(26) Lee, C. T.; Yang, W. T.; Parr, R. G. Development of the ColleSalvetti Correlation-Energy Formula into a Functional of the ElectronDensity. Phys. Rev. B 1988, 37, 785-789.

(27) Frisch, M. J.; Pople, J. A.; Binkley, J. S. Self-Consistent Molecular-Orbital Methods 0.25. Supplementary Functions for Gaussian-Basis Sets. J. Chem. Phys. 1984, 80, 3265-3269.

(28) Tomasi, J.; Mennucci, B.; Cammi, R. Quantum Mechanical Continuum Solvation Models. Chem. Rev. 2005, 105, 2999-3094.

(29) Zhao, Y.; Truhlar, D. The M06 Suite of Density Functionals for Main Group Thermochemistry, Thermochemical Kinetics, Noncovalent Interactions, Excited States, And Transition Elements: Two New Functionals and Systematic Testing of Four M06-Class Functionals and 12 Other Functionals. Theor. Chem. Acc. 2008, 120, $215-241$.

(30) Teklebrhan, R. B.; Owens, N. W.; Xidos, J. D.; Schreckenbach, G.; Wetmore, S. D.; Schweizer, F. Conformational Preference of Fused 
Carbohydrate-Templated Proline Analogues-A Computational Study. J. Phys. Chem. B 2012, 117, 199-205.

(31) Pipolo, S.; Cammi, R.; Rizzo, A.; Cappelli, C.; Mennucci, B.; Tomasi, J. Cavity Field Effects within a Polarizable Continuum Model of Solvation: Application to the Calculation of Electronic Circular Dichroism Spectra of R-(+)-3-Methyl-Cyclopentanone. Int. J. Quantum Chem. 2011, 111, 826-838.

(32) Mennucci, B.; Cappelli, C.; Cammi, R.; Tomasi, J. Modeling Solvent Effects on Chiroptical Properties. Chirality 2011, 23, 717729.

(33) Lopes Jesus, A. J.; S. F. Teixeira, M. H.; Redinha, J. S. Structure of Charged Cyclohexyldiamines in Aqueous Solution: A Theoretical and Experimental Study. J. Phys. Chem. B 2012, 116, 5019-5027.

(34) Atwood, R. E.; Urban, J. J. Conformations of the Glycine Tripeptide Analog Ac-Gly-Gly-NHMe: A Computational Study Including Aqueous Solvation Effects. J. Phys. Chem. A 2012, 116, 1396-1408.

(35) Møller, C.; Plesset, M. S. Note on an Approximation Treatment for Many-Electron Systems. Phys. Rev. 1934, 46, 618-622.

(36) Pople, J. A.; Binkley, J. S.; Seeger, R. Theoretical Models Incorporating Electron Correlation. Int. J. Quantum Chem. 1976, 10, $1-19$.

(37) Pople, J. A.; Seeger, R.; Krishnan, R. Variational Configuration Interaction Methods and Comparison with Perturbation theory. Int. J. Quantum Chem. 1977, 12, 149-163.

(38) Krishnan, R.; Pople, J. A. Approximate Fourth-Order Perturbation Theory of the Electron Correlation Energy. Int. J. Quantum Chem. 1978, 14, 91-100.

(39) Frisch, M. J.; Trucks, G. W.; Schlegel, H. B.; Scuseria, G. E.; Robb, M. A.; Cheeseman, J. R.; Scalmani, G.; Barone, V.; Mennucci, B.; Petersson, G. A.; Nakatsuji, H.; Caricato, M.; Li, X.; Hratchian, H. P.; Izmaylov, A. F.; Bloino, J.; Zheng, G.; Sonnenberg, J. L.; Hada, M.; Ehara, M.; Toyota, K.; Fukuda, R.; Hasegawa, J.; Ishida, M.; Nakajima, T.; Honda, Y.; Kitao, O.; Nakai, H.; Vreven, T.; Montgomery, J., J. A.; Peralta, J. E.; Ogliaro, F.; Bearpark, M.; Heyd, J. J.; Brothers, E.; Kudin, K. N.; Staroverov, V. N.; Kobayashi, R.; Normand, J.; Raghavachari, K.; Rendell, A.; Burant, J. C.; Iyengar, S. S.; Tomasi, J.; Cossi, M.; Rega, N.; Millam, N. J.; Klene, M.; Knox, J. E.; Cross, J. B.; Bakken, V.; Adamo, C.; Jaramillo, J.; Gomperts, R.; Stratmann, R. E.; Yazyev, O.; Austin, A. J.; Cammi, R.; Pomelli, C.; Ochterski, J. W.; Martin, R. L.; Morokuma, K.; Zakrzewski, V. G.; Voth, G. A.; Salvador, P.; Dannenberg, J. J.; Dapprich, S.; Daniels, A. D.; Farkas, Ö.; Foresman, J. B.; Ortiz, J. V.; Cioslowski, J.; Fox, D. J. Gaussian, Inc.; Wallingford CT, 2009.

(40) Cremer, D.; Pople, J. A. General Definition of Ring Puckering Coordinates. J. Am. Chem. Soc. 1975, 97, 1354-1358.

(41) Altona, C.; Sundaralingam, M. Conformational Analysis of the Sugar Ring in Nucleosides and Nucleotides. New Description Using the Concept of Pseudorotation. J. Am. Chem. Soc. 1972, 94, 82058212.

(42) Cremer, D. Calculation of Puckered Rings with Analytical Gradients. J. Phys. Chem. 1990, 94, 5502-5509.

(43) Bader, R. F. W. Atoms in Molecules: A Quantum Theory; Clarendon Press: Oxford, 1990.

(44) Popelier, P. L. A. Atoms In Molecules. An introduction; Prentice Hall: Harlow, England, 2000.

(45) Popelier, P. L. A. A robust algorithm to locate automatically all types of critical points in the charge density and its Laplacian. Chem. Phys. Lett. 1994, 228, 160-164.

(46) Popelier, P. L. A.; 0.2 ed. 1999.

(47) Rafat, M.; Popelier, P. L. A. Visualization and Integration of Quantum Topological Atoms by Spatial Discretization into Finite Elements. J. Comput. Chem. 2007, 28, 2602-2617.

(48) Keith, T. A.; 13.02 .26 ed. 2012.

(49) Cremer, D.; Kraka, E. Chemical Bonds without Bonding Electron Density - Does the Difference Electron-Density Analysis Suffice for a Description of the Chemical Bond? Angew. Chem. Int. Ed. 1984, 23, 627-628.
(50) Rozas, I.; Alkorta, I.; Elguero, J. Behavior of Ylides Containing $\mathrm{N}, \mathrm{O}$, and C Atoms as Hydrogen Bond Acceptors. J. Am. Chem. Soc. 2000, 122, 11154-11161.

(51) Weinhold, F.; Landis, C. R. Valency and Bonding. A Natural Bond Orbital Donor-Aceptor Perspective; Cambridge Press: Cambridge, 2005.

(52) Glendening, E. D.; Reed, A. E.; Carpenter, J. E.; Weinhold, F. NBO 3.1; Theoretical Chemistry Institute, University of Wisconsin, Madison, 2001.

(53) http://vicinv.ujaen.es/sti_cict.

(54) Real Crystal ${ }^{\circledR}$ IR sample cards; U.S. Patent No. 7,932,095 and U.K. Patent No. GB2372102.

(55) Kuroda, R.; Harada, T.; Shindo, Y. A solid-state dedicated circular dichroism spectrophotometer: Development and application. Rev. Sci. Instrum. 2001, 72, 3802-3810.

(56) Merten, C.; Kowalik, T.; Hartwig, A. Vibrational circular dichroism spectroscopy of solid polymer films: Effects of sample orientation. Appl. Spectrosc. 2008, 62, 901-905.

(57) Buffeteau, T.; Lagugné-Labarthet, F.; Sourisseau, C. Vibrational circular dichroism in general anisotropic thin solid films: Measurement and theoretical approach. Appl. Spectrosc. 2005, 59, 732-745.

(58) Barnett, C. B.; Naidoo, K. J. Ring Puckering: A Metric for Evaluating the Accuracy of AM1, PM3, PM3CARB-1, and SCC-DFTB Carbohydrate QM/MM Simulations. J. Phys. Chem. B 2010, 114, 17142-17154.

(59) Dowd, M. K.; French, A. D.; Reilly, P. J. MM3 Modeling of Ribose and 2-Deoxyribose Ring Puckering. J. Carbohydr. Chem. 2000, 19, 1091-1114.

(60) Steinmann, S. N.; Piemontesi, C.; Delachat, A.; Corminboeuf, C. Why are the Interaction Energies of Charge-Transfer Complexes Challenging for DFT? J. Chem. Theory Comput. 2012, 8, 1629-1640.

(61) Solimannejad, M.; Massahi, S.; Alkorta, I. Glyoxal Oligomers: A Computational Study. Int. J. Quantum Chem. 2011, 111, 3057-3069.

(62) Mata, I.; Alkorta, I.; Molins, E.; Espinosa, E. Universal Features of the Electron Density Distribution in Hydrogen-Bonding Regions: A Comprehensive Study Involving $\mathrm{H} \cdots \mathrm{X}(\mathrm{X}=\mathrm{H}, \mathrm{C}, \mathrm{N}, \mathrm{O}, \mathrm{F}, \mathrm{S}, \mathrm{Cl}, \pi)$ Interactions. Chem. Eur. J. 2010, 16, 2442-2452.

(63) Alkorta, I.; Rozas, I.; Elguero, J. Bond Length-Electron Density Relationships: From Covalent Bonds to Hydrogen Bond Interactions. Struct. Chem. 1998, 9, 243-247.

(64) Bender, M. L.; Brubacher, J. L. Catálisis y acción enzimática; Reverté: Spain, 1977.

(65) Voet, D.; Voet, J. G. Bioquímica, 3rd ed.; Editorial Médica Panamericana: Buenos Aires, 2006.

(66) Yang, G.; Pidko, E. A.; Hensen, E. J. M. Mechanism of Bronsted Acid-Catalyzed Conversion of Carbohydrates. J. Catal. 2012, 295, $122-132$.

(67) Lemieux, R. U.; Hendriks, K. B.; Stick, R. V.; James, K. Halide Ion Catalyzed Glycosidation Reactions. Syntheses of $\alpha$-Linked Disaccharides. J. Am. Chem. Soc. 1975, 97, 4056-4062. 